\title{
Climatological and radiative properties of midlatitude cirrus clouds derived by automatic evaluation of lidar measurements
}

\author{
Erika Kienast-Sjögren ${ }^{1, a}$, Christian Rolf ${ }^{2}$, Patric Seifert ${ }^{3}$, Ulrich K. Krieger ${ }^{1}$, Bei P. Luo ${ }^{1,4}$, Martina Krämer ${ }^{2}$, and \\ Thomas Peter $^{1}$ \\ ${ }^{1}$ Institute for Atmospheric and Climate Science, ETH Zurich, Switzerland \\ ${ }^{2}$ Institute for Energy and Climate Research, Stratosphere, Forschungszentrum Jülich, Jülich, Germany \\ ${ }^{3}$ Institute for Tropospheric Research (TROPOS), Leipzig, Germany \\ ${ }^{4}$ Physical Meteorological Observatory Davos, PMOD WRC, 7260 Davos, Switzerland \\ ${ }^{a}$ now at: Fed. Office of Meteorology and Climatology, MeteoSwiss, Zurich Airport, \\ Operation Center 1, 8058 Zurich, Switzerland \\ Correspondence to: Erika Kienast-Sjögren (erika.kienast@meteoswiss.ch)
}

Received: 14 January 2016 - Published in Atmos. Chem. Phys. Discuss.: 2 February 2016

Revised: 18 May 2016 - Accepted: 23 May 2016 - Published: 22 June 2016

\begin{abstract}
Cirrus, i.e., high, thin clouds that are fully glaciated, play an important role in the Earth's radiation budget as they interact with both long- and shortwave radiation and affect the water vapor budget of the upper troposphere and stratosphere. Here, we present a climatology of midlatitude cirrus clouds measured with the same type of ground-based lidar at three midlatitude research stations: at the Swiss high alpine Jungfraujoch station (3580 m a.s.l.), in Zürich (Switzerland, $510 \mathrm{~m}$ a.s.l.), and in Jülich (Germany, $100 \mathrm{~m}$ a.s.l.). The analysis is based on $13000 \mathrm{~h}$ of measurements from 2010 to 2014. To automatically evaluate this extensive data set, we have developed the Fast LIdar Cirrus Algorithm (FLICA), which combines a pixel-based clouddetection scheme with the classic lidar evaluation techniques. We find mean cirrus optical depths of 0.12 on Jungfraujoch and of 0.14 and 0.17 in Zürich and Jülich, respectively.

Above Jungfraujoch, subvisible cirrus clouds $(\tau<0.03)$ have been observed during $6 \%$ of the observation time, whereas above Zürich and Jülich fewer clouds of that type were observed. Cirrus have been observed up to altitudes of $14.4 \mathrm{~km}$ a.s.l. above Jungfraujoch, whereas they have only been observed to about $1 \mathrm{~km}$ lower at the other stations. These features highlight the advantage of the high-altitude station Jungfraujoch, which is often in the free troposphere above the polluted boundary layer, thus enabling lidar measurements of thinner and higher clouds. In addition, the measurements suggest a change in cloud morphology at
\end{abstract}

Jungfraujoch above $\sim 13 \mathrm{~km}$, possibly because high particle number densities form in the observed cirrus clouds, when many ice crystals nucleate in the high supersaturations following rapid uplifts in lee waves above mountainous terrain.

The retrieved optical properties are used as input for a radiative transfer model to estimate the net cloud radiative forcing, $\mathrm{CRF}_{\mathrm{NET}}$, for the analyzed cirrus clouds. All cirrus detected here have a positive $\mathrm{CRF}_{\mathrm{NET}}$. This confirms that these thin, high cirrus have a warming effect on the Earth's climate, whereas cooling clouds typically have cloud edges too low in altitude to satisfy the FLICA criterion of temperatures below $-38^{\circ} \mathrm{C}$. We find $\mathrm{CRF}_{\mathrm{NET}}=0.9 \mathrm{~W} \mathrm{~m}^{-2}$ for Jungfraujoch and $1.0 \mathrm{~W} \mathrm{~m}^{-2}\left(1.7 \mathrm{~W} \mathrm{~m}^{-2}\right)$ for Zürich (Jülich). Further, we calculate that subvisible cirrus $(\tau<0.03)$ contribute about $5 \%$, thin cirrus $(0.03<\tau<0.3)$ about $45 \%$, and opaque cirrus $(0.3<\tau)$ about $50 \%$ of the total cirrus radiative forcing.

\section{Introduction}

One of the main challenges in climate modeling, characterized by a low level of scientific understanding, is clouds and their effects on climate (Dessler and Yang, 2003; Solomon et al., 2007; Boucher et al., 2013). This concerns also the microphysical processes leading to cirrus formation. These processes are subject to uncertainties in the understanding and parametrization of homogeneous and heterogeneous nu- 
cleation (e.g., Cirisan et al., 2014). For any specific cloud scene, unless there are in situ measurements, there is either no or incomplete knowledge of the number of ice nuclei, the intensity of small-scale temperature fluctuations, or the corresponding accurate values of upper tropospheric humidity (e.g., Rolf et al., 2012; Ickes et al., 2015; Kienast-Sjögren et al., 2015).

Cloud properties such as cloud particle number, size, and ice particle shape determine ice water content and optical depth, which together with the temperature of the cirrus cloud top determine whether the net cloud radiative forcing is positive or negative, i.e., whether a particular cirrus cloud is warming or cooling (Platt and Harshvardhan, 1988; Ebert and Curry, 1992; Lin et al., 1998a; Chen et al., 2000; Corti and Peter, 2009a). The fact that liquid clouds contain spherical particles helps to estimate their microphysical and radiative properties. Conversely, the different shapes and orientations (Pruppacher and Klett, 1997) of ice particles affect the extinction of light, complicating the estimation of the cirrus climate effect (Fu and Liou, 1993; Liou, 2002). Previous studies of the radiative effect of cirrus (e.g., Chen et al., 2000; Fusina et al., 2007; Cziczo and Froyd, 2014) have identified a range of several watts per square meter $\left(\mathrm{W} \mathrm{m}^{-2}\right)$ depending on the ice crystal number in a cirrus as compared to having an ice-free supersaturated region.

Lidar (light detection and ranging) measurements can be used to establish long time series of aerosol or cloud measurements (e.g., Platt et al., 1994). From the co- and crosspolarized components of the backscattered light the profile of the depolarization ratio can be obtained, providing information about the sphericity of the retrieved particles and thus their liquid or solid state. Several lidar stations have applied their measurements of elastically backscattered light to investigate the properties of midlatitude cirrus clouds. See Table 1 for an overview.

Here we present a cirrus cloud climatology based on $13000 \mathrm{~h}$ of lidar measurements from three midlatitude sites: Jungfraujoch, Zürich, and Jülich. The lidar technique is briefly described in Sect. 2.1. In Sect. 2.2, the newly developed evaluation algorithm Fast LIdar Cirrus Algorithm (FLICA) is presented. Using FLICA we are able to analyze extensive lidar measurements automatically. The climatology of this data is presented in Sect. 3. We then apply the radiative transfer model of Corti and Peter (2009a) to estimate the cloud radiative forcing caused by the detected cirrus clouds in Sect. 4. The results are compared to previous studies in Sect. 4.2. The influence of the thinnest, subvisible cirrus clouds on the cirrus radiative forcing (CRF) is examined in Sect. 4.3. Finally, the main findings are summarized in Sect. 5.

\section{Lidar}

\subsection{Lidar technique}

This work uses the commercially available elastic backscatter lidar Leosphere ALS 450. This lidar emits linearly polarized laser pulses with an energy of $16 \mathrm{~mJ}$ at a wavelength of $355 \mathrm{~nm}$ and a repetition rate of $20 \mathrm{~Hz}$. The full-angle field of view of the receiver telescope and the laser beam divergence are 1.5 and $0.3 \mathrm{mrad}$, respectively.

The Nd:YAG laser of the ALS 450 is powered by a flash lamp. The flash lamp has a lifetime corresponding to $5 \times 10^{7}$ shots or $694 \mathrm{~h}$ or a month of continuous operation. In order to save flash lamp lifetime, the ALS 450 operated at Zürich and on the Jungfraujoch was coupled to a Vaisala Ceilometer CL31, which is a simple, low-maintenance elastic backscatter lidar (with a pulse energy about 3 orders of magnitude lower than the ALS 450). We use the ceilometer to detect thick clouds at low altitudes. Once thick clouds are present at an altitude lower than $1 \mathrm{~km}$ above the station, the lidar is automatically switched off (this is the case at roughly $30-40 \%$ of the time), and it is automatically switched back on once the low-level clouds are gone. In Jülich, where no ceilometer was available, the ALS 450 was operated manually and switched off and on after visual inspection.

The range-corrected signal $r^{2} P(r)$ detected by the ALS 450 can be described with the lidar equation (Kovalev and Eichinger, 2004; Wandinger, 2005):

$$
\begin{aligned}
r^{2} P(r)= & C \times O(r)\left[\beta_{\mathrm{m}}(r)+\beta_{\mathrm{p}}(r)\right] \exp \left(-2 \int_{r_{0}}^{r}\left[\alpha_{\mathrm{m}}\left(r^{\prime}\right)\right.\right. \\
& \left.\left.+\alpha_{\mathrm{p}}\left(r^{\prime}\right)\right] \mathrm{d} r^{\prime}\right),
\end{aligned}
$$

where $\beta_{\mathrm{m}}$ and $\beta_{\mathrm{p}}$ describe the backscatter from molecules and particles and $\alpha_{\mathrm{m}}$ and $\alpha_{\mathrm{p}}$ specify molecular and particulate extinctions, i.e., light attenuation by scattering and absorption, and take changes of scatterer density with altitude into account. Instrumental properties are described by the constant $C . O(r)$ is the overlap function which describes the overlap between the laser footprint and the telescope field of view. For the ALS 450 the complete overlap is achieved at a distance of $450 \mathrm{~m}$ from the lidar. As we analyze cirrus clouds that occurred entirely at greater heights above the lidar, we do not need to consider the overlap function.

The Leosphere ALS 450 measures the co- and crosspolarized components of the return signal. In order to solve Eq. (1) it is required to obtain the total signal from these two components. We calculate the total signal based on both channels as described by Rolf (2012).

From the detected co- and cross-polarized signal components the depolarization ratio can be obtained (Schotland et al., 1971). We assume an ideal lidar system, which means that there is no cross-talk between the co-polarized and the 
Table 1. Lidar stations that have been used for systematic climatological studies of cirrus clouds in the midlatitudes.

\begin{tabular}{llrrrrl}
\hline $\begin{array}{l}\text { Measurement } \\
\text { site }\end{array}$ & Location & $\begin{array}{r}\text { Altitude } \\
(\mathrm{m} \text { a.s.l.) }\end{array}$ & $\begin{array}{r}\text { Observation } \\
\text { period }\end{array}$ & $\begin{array}{r}\text { Wavelength } \\
(\mathrm{nm})\end{array}$ & $\begin{array}{r}\text { Hours } \\
\text { of data }\end{array}$ & References \\
\hline Salt Lake City, USA & $42^{\circ} \mathrm{N}, 68^{\circ} \mathrm{W}$ & 1726 & $1986-1996$ & 694 & 2200 & $\begin{array}{l}\text { Sassen and Campbell (2001); Sassen and Benson (2001); } \\
\text { Sassen and Comstock (2001); Sassen et al. (2003, 2007) }\end{array}$ \\
& & & & & & \\
Punta Arenas, Chile & $53^{\circ} \mathrm{S}, 71^{\circ} \mathrm{W}$ & 126 & Mar-Apr 2000 & 355,532 & 71 & Immler and Schrems (2002) \\
Prestwick, Scotland & $56^{\circ} \mathrm{N}, 5^{\circ} \mathrm{W}$ & 7 & Sep-Oct 2000 & 355,532 & 74 & Immler and Schrems (2002) \\
Haute Provence, France & $44^{\circ} \mathrm{N}, 6^{\circ} \mathrm{E}$ & 679 & $1997-2012$ & 532,1064 & $\sim 7000$ & Goldfarb et al. (2001); Hoareau et al. (2013) \\
Rome Tor Vergata, Italy & $42^{\circ} \mathrm{N}, 13^{\circ} \mathrm{E}$ & 107 & $2007-2010$ & 532 & 500 & Dionisi et al. (2013) \\
Clermont-Ferrand, France & $46^{\circ} \mathrm{N}, 3^{\circ} \mathrm{E}$ & 420 & $2008-2014$ & 355 & $\sim 2000$ & Fréville et al. (2015) \\
Seoul, South Korea & $37^{\circ} \mathrm{N}, 127^{\circ} \mathrm{E}$ & 116 & $2006-2009$ & 532,1064 & $\sim 1000$ & Kim et al. (2014) \\
Jülich, Germany & $51^{\circ} \mathrm{N}, 6^{\circ} \mathrm{E}$ & 95 & $2011-2013$ & 355 & 3274 & This work, also Rolf (2012) \\
Zürich, Switzerland & $47^{\circ} \mathrm{N}, 9^{\circ} \mathrm{E}$ & 509 & $2010-2013$ & 355 & 4678 & This work \\
Jungfraujoch, Switzerland & $47^{\circ} \mathrm{N}, 8^{\circ} \mathrm{E}$ & 3580 & $2010-2014$ & 355 & 5170 & This work \\
\hline
\end{tabular}

cross-polarized channels. Rolf (2012) has examined this for the lidar used in Jülich. He found that, for the parallel detector, every 2000th detected photon is actual perpendicular polarized and for the perpendicular detector about every 570 detected photon is parallel polarized. While this justifies our assumption of an ideal system for the Jülich lidar, we found considerable cross-talk in the Swiss lidar, depending on certain maintenance conditions. However, cross-talk influences in particular the perpendicular channel, which we use mainly for cloud detection but not for optical depth retrieval. Light that is scattered back by non-spherical particles changes its polarization state, whereas spherical particles do not change the state of polarization of the returned light. Therefore, the depolarization ratio provides information about the sphericity of the detected particles (Schotland et al., 1971; Kovalev and Eichinger, 2004). The cross-polarized signal from aspherical ice particles in thin cirrus often provides the better contrast than the parallel signal, a property we will use in our cloud retrieval algorithm. The lidar is pointed to $5^{\circ}$ off-zenith to avoid the effect of specular reflections of horizontally oriented ice crystal plates on the measured backscatter signal and depolarization ratio (Platt et al., 1978; Westbrook et al., 2010).

For our cloud detection scheme elaborated in Sect. 2.2, we use the backscatter ratio (BSR) defined as

$\mathrm{BSR}=\frac{\beta_{\mathrm{p}}+\beta_{\mathrm{m}}}{\beta_{\mathrm{m}}}$.

To solve the lidar equation (Eq. 1) with four unknowns $\left(\beta_{\mathrm{m}}\right.$, $\beta_{\mathrm{p}}, \alpha_{\mathrm{m}}$, and $\left.\alpha_{\mathrm{p}}\right)$ and only one measurement $r^{2} P(r)$, we need to make use of best current knowledge. The molecular quantities $\beta_{\mathrm{m}}$ and $\alpha_{\mathrm{m}}$ are calculated from analysis data of the numerical weather prediction model (NWP) COSMO2 . We use pressure $(p)$ and temperature $(T)$ from COSMO2 (COSMO, 2015) to calculate the molecular density of air and determine $\beta_{\mathrm{m}}$ and $\alpha_{\mathrm{m}}$ using Rayleigh theory (Bucholtz, 1995).

For the solution of Eq. (1) we use a lidar retrieval as described in Kovalev and Eichinger (2004). To ensure stable solutions, we use a far-end boundary condition (Klett, 1981).
Further, we need to define the extinction-to-backscatter ratio (hereafter referred to as lidar ratio). We derive $\epsilon=0.234$, the anisotropy of the molecules present in the atmosphere, from Eq. (6) in She (2001) and Table 1 in Bucholtz (1995) for our lidar wavelength of $355 \mathrm{~nm}$. The lidar ratio of the molecular part is evaluated as

$L_{\mathrm{m}}=\frac{8 \pi}{3} \times \frac{180+40 \epsilon}{180+7 \epsilon} \approx 8.7$,

where $\sigma^{R}$, given by Eq. (6) of She (2001), is divided by the expression for $\sigma_{\pi}^{C}$, provided in Eq. (4) of She (2001), as the receiver optical bandpass spectral width of $0.3 \mathrm{~nm}$ $\left(<24 \mathrm{~cm}^{-1}\right.$ at $\left.28170 \mathrm{~cm}^{-1}\right)$ suppresses the rotational Raman wing spectral contribution (Arshinov and Bobrovnikov, 1999). Note that our $\epsilon$ is called $R_{\mathrm{A}}$ by She (2001). The particulate lidar ratio is defined as

$L_{\mathrm{p}}=\frac{\alpha_{\mathrm{p}}}{\beta_{\mathrm{p}}}$.

Several studies have been performed to measure the particulate lidar ratio of cirrus clouds (e.g., Ansmann et al., 1992; Ackermann, 1998; Immler and Schrems, 2002; Larchevêque et al., 2002; Seifert et al., 2007). It can be obtained directly from Raman lidars that allow for an independent measurement of particle extinction and backscatter coefficients (Cooney, 1972; Giannakaki et al., 2007; Radlach et al., 2008; Reichardt et al., 2002; Achtert et al., 2013) as well as from high-spectral-resolution lidar (HSRL) measurements (e.g., Burton et al., 2012). In our retrieval we determine the lidar ratio such that $\mathrm{BSR}=1$ above and below the cirrus cloud (e.g., Rolf, 2012).

The lidar equation (Eq. 1) assumes single scattering of the emitted light in the direction $180^{\circ}$ to the emitted direction only. In reality, this is not strictly the case. As seen in Fig. 1 in Wandinger (1998), cloud particles produce strong forward scattering. This causes some of the scattered photons to remain within the field of view of the lidar, where they can be scattered back to the lidar receiver during a subsequent scattering process. These additional backscattered photons cause an underestimation of the particle extinction. The strength 


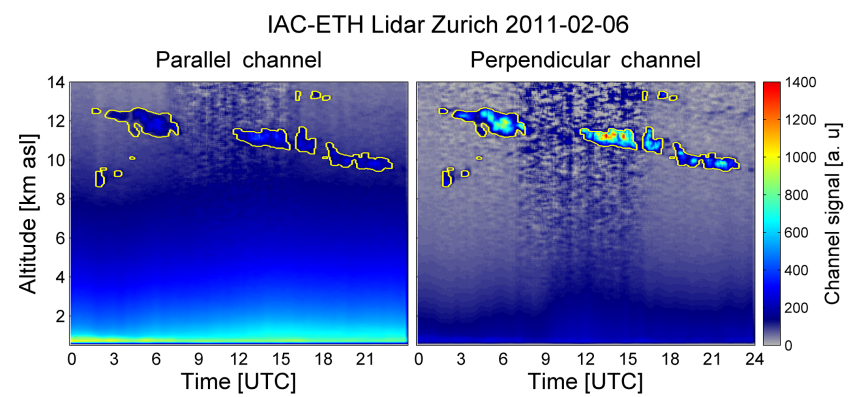

Figure 1. Cloud detection applied to a lidar measurement from Zürich: co-polarized (left) and cross-polarized (right) channel.

of multiple scattering depends mainly on the laser divergence, the telescope field of view, and the effective radius of the scattering particles (Wandinger et al., 2010). In order to provide extinction values that are comparable to other lidar systems and cloud conditions, the measured apparent, multiple-scattering, affected extinction coefficient $\alpha_{\mathrm{p}}^{\text {obs }}$ needs to be corrected with the correction factor $\gamma$ to obtain singlescattering related values $\alpha_{\mathrm{p}}^{\text {single }}$, such that

$\alpha_{\mathrm{p}}^{\text {single }}=\frac{\alpha_{\mathrm{p}}^{\mathrm{obs}}}{\gamma}$

We use the multiple-scattering model by Hogan (2008) as described by Wandinger (1998) and Seifert et al. (2007) to derive $\gamma$. The effective radius of the cirrus particles is taken from a climatology provided by Wang and Sassen (2002). For particles much larger than the detection wavelength, as is the case for ice crystals observed with lidar, about $50 \%$ of the scattering occurs into the forward direction. In this study we find an average value for $\gamma$ of 0.56 for Jungfraujoch and 0.52 (0.54) for Zürich (Jülich).

The lidar retrieval poses several uncertainties. Using NWP data to calculate the molecular properties results in a maximal error of $2 \%$. However, there are uncertainties pertained to the data themselves. The lidar detector counts photons, and we calculate the counting error by means of poisson statistics. The assumed lidar ratio is also an error source. Here, we use lidar ratios that deviate $\pm 5 \mathrm{sr}$ from the determined lidar ratios to assess for the uncertainty caused by determining a lidar ratio. To assess the total maximum uncertainty, we combine the individual contributions to provide an upper bound of the uncertainty. We calculate the largest possible error, which usually is larger than the error calculated by a Gaussian error (square root of the sum of the squares of the individual contributions). Seifert et al. (2007) estimated the error in the multiple-scattering correction on the order of $10 \%$. The signal-to-noise ratio (SNR) is determined by the variation within the 5 min average profiles. As the Leosphere lidar does not allow to retrieve the photon counts directly from the data, we calculate the SNR from the original lidar profiles as

$\mathrm{SNR}=\sqrt{N} \cdot \frac{\operatorname{mean}\left(r^{2} P(r)\right)}{\mathrm{SD}\left(r^{2} P(r)\right)}$,

where mean $\left(r^{2} P(r)\right)$ is the mean range-corrected signal and $\mathrm{SD}\left(r^{2} P(r)\right)$ is the standard deviation of the originally retrieved lidar profiles over $N=600$ shots (following a suggestion by P. Royer, Leosphere, personal communication, 11 August 2014).

\subsection{Cirrus detection algorithm FLICA}

For an efficient evaluation of this extensive data set, the automated data evaluation algorithm FLICA was developed. The algorithm is based on a classical lidar retrieval (e.g., Klett, 1981; Kovalev and Eichinger, 2004) combined with a cloud detection scheme. FLICA analyzes profiles over $5 \mathrm{~min}$ (i.e., averages over $5 \mathrm{~min} \times 60 \mathrm{~s} \mathrm{mins}^{-1} \times 20$ shots s${ }^{-1}=6000$ shots). This time range was chosen to be short enough to ensure that all clouds could be detected by the algorithm while also long enough to provide profiles smooth enough for the lidar retrieval to function. The $5 \mathrm{~min}$ profiles of the lidar measurements are further smoothed using a moving average boxcar filter in the vertical coordinate over $150 \mathrm{~m}$ and 5 profiles in time to reduce the noise level and hence simplify the automatic evaluation by FLICA.

The output of the cloud detection scheme has been visually inspected for individual days and was found not to show any apparent artifacts. There is a trade-off between detecting cloud structures small enough and avoiding misclassifying noise as a cloud, especially for daytime measurements. The combination of the criteria below represents a rather conservative approach, which might result in missing some particularly small/thin clouds. The conservative approach ensures that no noise is misclassified as a cirrus cloud. An example of the resulting cloud detection can be seen in Fig. 1.

The FLICA algorithm contains the following steps.

i. Cloud top detection. The cloud top is needed as an upper boundary for the subsequent lidar retrieval. Our cloud top detection averages individual lidar profiles so that the resolution of one pixel is $5 \mathrm{~min}$ in time and $30 \mathrm{~m}$ in altitude. Areas of $3 \times 3$ pixels are examined, with the pixel to be checked for cloudiness in the center. At least eight of the nine examined pixels have to have a volume depolarization larger than $0.007(0.006)$ for day(night)time measurements. At least eight of nine pixels also have to have larger co- and cross-polarized raw signals than empirical thresholds.

ii. Setting the far-end boundary condition for the lidar retrieval. The mean of the co-polarized signal at altitudes from detected cloud top to $500 \mathrm{~m}$ above cloud top is computed for each profile individually and 
used as far-end boundary condition for the lidar retrieval as described in Klett (1981). At this boundary, we assume a BSR of 1 . This assumption introduces no error if the aerosol density above the cloud is the same as the one of the interstitial aerosol. If these densities were different, we estimate from our in situ observations (http://www.iac.ethz.ch/groups/peter/ research/Balloon_soundings/COBALD_sensor) that the error introduced would be of the order of $1-2 \%$.

iii. Lidar retrieval. The lidar retrieval is performed as described in chap. 5 in Kovalev and Eichinger (2004) to solve the lidar equation (Eq. 1) and calculate the extinction coefficients and BSR of the cirrus cloud. The retrieval is performed for a set of lidar ratios between 5 and $40 \mathrm{sr}$, in steps of $5 \mathrm{sr}$. The best choice was determined such that BSR is closest to 1 below the cirrus cloud. The BSR is corrected during the retrieval such that the mean BSR in the range $500 \mathrm{~m}$ above the cloud top is equal to 1 .

iv. Cirrus cloud detection. The cloud detection scheme is based on the retrieved BSR and volume depolarization as follows.

Resolution of one pixel: $5 \mathrm{~min}$ in time, $30 \mathrm{~m}$ in altitude.

Areas of $3 \times 3$ pixels are examined, with the pixel to be checked for cloudiness in the center. At least eight of the nine examined pixels have to have a volume depolarization larger than $0.007(0.006)$ and a BSR larger than 1.08(1.03) for day(night)-time measurements.

Temperature has to be lower than $-38^{\circ} \mathrm{C}$ (e.g., Pruppacher and Klett, 1997; Koop et al., 2000; Krämer et al., 2016) to ensure pure ice clouds and avoid detecting mixed-phase clouds (this is checked using COSMO-2 or COSMO-7 analysis data).

The detection is applied to each pixel at each time independently.

Clouds extending less than $150 \mathrm{~m}$ in altitude during daytime conditions are not further taken into account (as noise-limiting measure), whereas nighttime clouds are allowed to be as thin as $3 \times 30 \mathrm{~m}=90 \mathrm{~m}$.

Cloud pixels separated vertically by less than $150 \mathrm{~m}$ are merged into one cloud layer.

The detected cloud top and cloud base, $h_{\text {top }}$ and $h_{\text {base, }}$ are stored.

v. Multiple-scattering correction. The single-scattering extinction coefficients are derived from the apparent, multiple-scattering, affected extinction coefficients as described in Sect. 2.1. We use the multiple-scattering model of Hogan (2008) as described in Wandinger (1998) and Seifert et al. (2007).

vi. Optical depth. The optical depth $\tau$ of the detected cirrus cloud is calculated by integrating over the retrieved extinction profiles.

$$
\tau=\int_{h_{\text {base }}}^{h_{\text {top }}} \alpha_{\mathrm{p}}(r) \mathrm{d} r
$$

vii. Radiative effect. The optical depth $\tau$ combined with temperatures from COSMO-2 or COSMO-7 is used to calculate the radiative effect of the cirrus cloud by means of the model of Corti and Peter (2009a).

\section{Lidar cirrus climatology}

\subsection{Measurement sites}

Here we present the retrieved lidar cirrus climatology. First, a description of the different measurement sites shown in Fig. 2 is provided. Subsequently, we present the climatology of the cirrus cloud properties. The section ends with a comparison of our data with previous midlatitude climatology studies.

\subsubsection{Jungfraujoch}

Jungfraujoch is the highest measurement site used in this study. It is located in the Swiss Alps $\left(46.55^{\circ} \mathrm{N}, 7.99^{\circ} \mathrm{E}\right)$ at $3580 \mathrm{~m}$ a.s.l. at the top of the Aletsch glacier. Due to its high elevation, the research station is frequently situated in the free troposphere (Zieger et al., 2012), which is a great advantage for lidar measurements. The Sphinx Observatory, where our measurements took place, is one of the Global Atmospheric Watch (GAW) research stations. Therefore, long time series of meteorological measurement data are available for this site. Due to its high location and cold climate, the site poses challenges for instruments being able to run continuously. The Leosphere ALS 450 used in this study was built into a ventilated, temperature-controlled, and regulated containment.

\subsubsection{Zürich}

Zürich $\left(47.37^{\circ} \mathrm{N}, 8.55^{\circ} \mathrm{E}\right)$, the largest city in Switzerland, is situated in the northern part of Switzerland at $408 \mathrm{~m}$ a.s.l., within the Swiss Plateau. The Swiss Plateau is surrounded by the Alps and Jura mountains, which create a basin through which air masses originating from the Atlantic Ocean are funneled. Therefore, the predominant wind direction in Zürich is from the southwest. Although the Swiss plateau is a large basin, it is still hilly. Lake Zürich is a basin itself within the Swiss plateau, and the city of Zürich is situated on the 


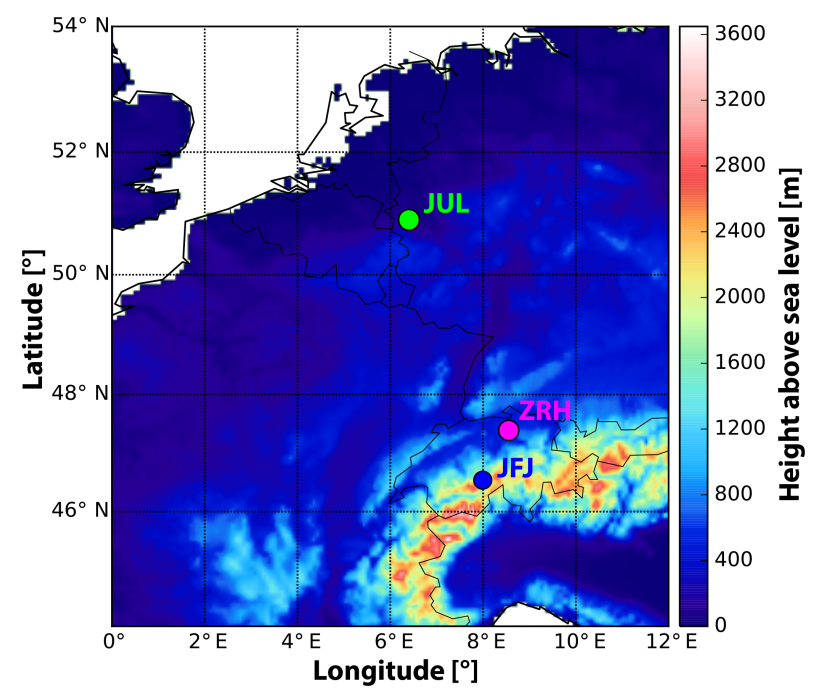

Figure 2. Location of the measurements sites Jülich (JUL), Jungfraujoch (JFJ), and Zürich (ZRH). Color-coded: topography in COSMO-7. Black lines: national borders (National Geophysical Data Center, 1993).

lake's northern shore. Lidar measurements were taken from the roof of ETH's Institute for Atmospheric and Climate Science (IAC), which is $500 \mathrm{~m}$ a.s.l. and located in the middle of Zürich. Aerosol particles in and around Zürich arise from industry, transportation and housing, and the large airport nearby. In contrast to Jungfraujoch, such additional aerosol sources cause low-level extinction of the emitted laser pulse.

\subsubsection{Jülich}

The Research Center Jülich is located $91 \mathrm{~m}$ a.s.l. in the western part of middle Germany $\left(50.91^{\circ} \mathrm{N}, 6.40^{\circ} \mathrm{E}\right)$ between the larger cities Aachen and Köln in North Rhine-Westphalia. Due to its low elevation and location close to the Netherlands, the weather fronts arrive more or less directly from the Atlantic Ocean without moderation by orography. The terrain around Jülich is relatively flat. The research center itself is located in a rural area and therefore the lidar measurements might be less influenced by boundary layer aerosol than the Zürich measurements, despite nearby brown coal industry activity.

\subsection{Cirrus climatology}

Following Sect. 2.2 we present the climatological evaluation of more than $13000 \mathrm{~h}$ of lidar measurements within the period 2010-2014 from the three midlatitude measurement sites. The main information on the measurement statistics for the three sites is compiled in Table 2. More measurements are available from Jungfraujoch and Zürich than from Jülich. For Jungfraujoch, most of the data were retrieved in the spring, whereas during the summer only very limited data are available. In Zürich, in contrast, a large number of the measurements took place during the summer, while the other seasons show similar coverage. The Jülich lidar was running predominantly during spring and summer, while the autumn and winter data are sparse. The amount of data has to be considered when judging seasonal variability. The retrieved cirrus properties listed in Table 2 indicate a temporal cirrus cloud coverage between 9 and $15 \%$ for all stations, agreeing well with the CALIPSO measurements discussed by Sassen et al. (2008) and being slightly smaller than the 18-19\% measured during the ECLIPS campaign by Winker and Vaughan (1994).

The seasonal dependence of the observed cirrus coverage is displayed in Fig. 3. The most striking feature is the difference between the wintertime measurements in Zürich and Jungfraujoch, showing a cirrus coverage of around $12 \%$, while in Jülich this is about $33 \%$. This is in qualitative agreement with geographical maps of high cloud amount (cloud pressure smaller than $440 \mathrm{hPa}$ ) for January observed by the TIROS-N Operational Vertical Sounder (TOVS) averaged over 8 years, 1987-1995 (http://ara.abct.lmd.polytechnique. fr/index.php?page=clouds). For January, these data suggest decreasing amounts of high clouds when the air passes from the North Sea towards the Alps. Also, a time series of 40 years of measurements of turbidity in Jülich confirms the high cloud coverage during wintertime (A. Knaps, personal communication, Forschungszentrum Jülich, 2014). However, there are large uncertainties in this part of our climatology, as the number of hours of measurements with the Leosphere ALS 450 available for the Jülich winter is small (Table 2), the specific winter might have had a particularly high cirrus cloud coverage, and the applied manual operation of the lidar might add bias. Another remarkable feature is the autumn maximum in cirrus coverage observed above Jungfraujoch. This feature is also in qualitative agreement with the seasonal cycle suggested by the TOVS data set; interannual variability might again be important but cannot be derived from our measurements.

The first property of interest is the distribution of the optical depths of the detected cirrus clouds, which we classify according to Sassen and Cho (1992) (cf. Table 2): clouds with an optical depth $\tau<0.03$ are not visible to the naked eye and hence termed subvisible. Cirrus clouds with an optical depth $\tau$ in the range $0.03 \leq \tau<0.3$ are termed thin, while clouds with $\tau \geq 0.3$ are referred to as opaque. The upper limit of detection for our lidars is $\tau \approx 3$; as for larger optical depths, the light is almost fully extinguished within the cloud. Under these conditions no molecular signal from above the cloud can be detected (Immler and Schrems, 2002), as would be required for an inversion. Therefore, we are not able to specify the optical thickness of the thickest cirrus clouds. Chen et al. (2000) classified clouds with tops above $440 \mathrm{hPa}(\approx 6500 \mathrm{~m})$ and optical depths larger than 3.6 as cirrostratus. These cirrus clouds may have a negative cloud radiative effect but cannot be considered here because of the detection limits of our lidar instrument. 
Table 2. Properties of the cirrus clouds detected between 2010 and 2014.

\begin{tabular}{|c|c|c|c|}
\hline & JFJ & Zürich & Jülich \\
\hline \multicolumn{4}{|l|}{ General properties } \\
\hline Hours of measurements ${ }^{\mathrm{a}}$ & 5170 & 4678 & 3274 \\
\hline Number of cirrus detected ${ }^{b}$ & 10295 & 6021 & 7184 \\
\hline Cirrus cloud coverage in $\%^{\mathrm{c}}$ & 14 & 9 & 15 \\
\hline Low cloud coverage in $\% \mathrm{~d}$ & 15 & 8 & 26 \\
\hline Clear sky in $\% \mathrm{e}$ & 71 & 83 & 59 \\
\hline \multicolumn{4}{|c|}{ Fraction of measurement time by season in $\%$} \\
\hline DJF & 24 & 17 & 18 \\
\hline MAM & 40 & 15 & 39 \\
\hline JJA & 14 & 48 & 31 \\
\hline SON & 22 & 20 & 12 \\
\hline
\end{tabular}

Cloud occurrence frequencies in categories according to Sassen and Cho (1992)

(expressed as fraction of "number of cirrus detected")

$\begin{array}{lrrr}\text { Subvisible cirrus }(\tau<0.03) \text { in } \% & 43 & 35 & 32 \\ \text { Thin cirrus }(0.03<\tau<0.3) \text { in } \% & 46 & 52 & 51 \\ \text { Opaque cirrus }(0.3<\tau) \text { in } \% & 11 & 13 & 17 \\ \text { Mean } \tau^{\mathrm{f}} & 0.12_{-.06}^{+.02} & 0.14_{-.08}^{+.02} & 0.17_{-.08}^{+.02} \\ \text { Measurement period } & 07 / 10-08 / 10 & 05 / 10-06 / 10 & 04 / 11-08 / 11 \\ \text { MM/YY) } & 11 / 11-06 / 12 & 10 / 10-10 / 11 & 11 / 11-09 / 12 \\ & 09 / 13-04 / 14 & 07 / 13-09 / 13 & 04 / 13-12 / 13\end{array}$

a Refers to the number of hours lidar measurements with the ALS 450. Not included are times when the ceilometer detected low-level clouds closer than $1.5 \mathrm{~km}$

$\mathrm{b}$ According to the specifications of the FLICA algorithm, see Sect. 2.2.

c This compares reasonably well with $11 \%$ zonal average by Chen et al. (2000).

${ }^{\mathrm{d}}$ Refers only to clouds at least $1 \mathrm{~km}$ above the lidar.

e As observed by the ALS 450 .

${ }^{\mathrm{f}}$ Uncertainties as described in the last paragraph of Sect. 2.1. Mean values of $\tau$ compare reasonably well with monthly mean $\tau$ values of $0.1-0.2$ from ISCCP (Soden and Donner (1994); also

http://www.gfdl.noaa.gov/ice-clouds-in-the-skyhi-general-circulation-model).

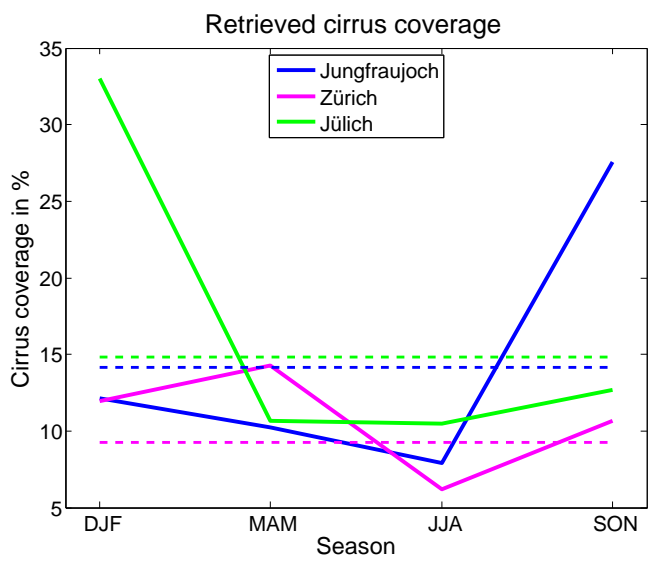

Figure 3. Seasonal cycle of cirrus cloud coverage for the three measurement sites. Dashed lines: annual means.

Figure $4 \mathrm{~b}$ shows the optical depth of the retrieved cirrus clouds for different seasons. The grey dashed lines indicate the categories defined by Sassen and Cho (1992). The optical depth averaged over the whole data sets for each measurement site is displayed in Fig. 4a. These $\tau$ values agree well with the ECLIPS campaign (Pal et al., 1995),

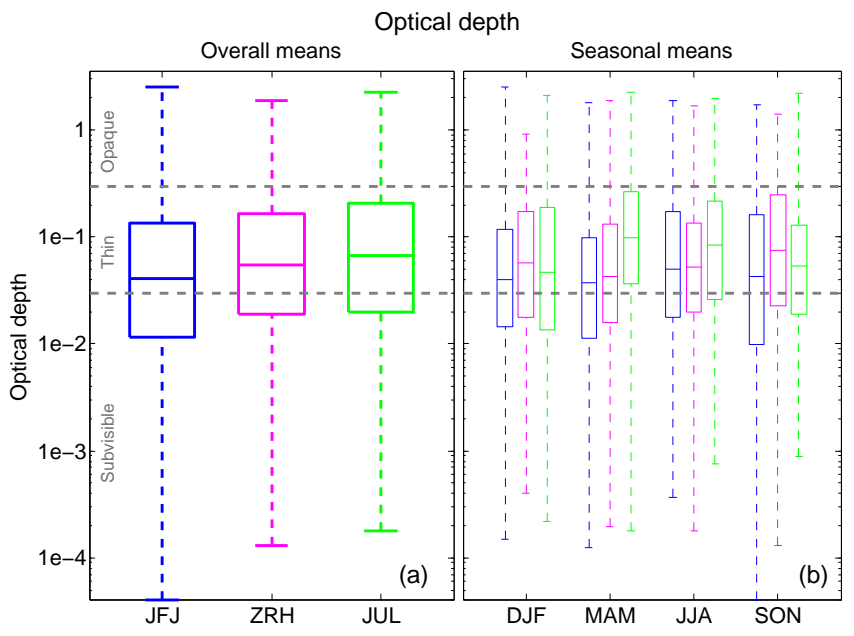

Figure 4. Optical depths of the three measurement sites. (a) Means across whole data set. (b) Seasonal cycle of optical depth. Horizontal line in box: median. Boxes: the upper and lower quartile. Whisker: extremes. Gray horizontal lines: cirrus categories by Sassen and Cho (1992). 
where most detected cirrus clouds had optical depths smaller than 0.1. A Wilcoxon Rank sum test reveals that the optical depth distributions of the different sites are significantly different from each other. The occurrence frequency of subvisible cirrus clouds is larger for Jungfraujoch than for the other two sites. Two reasons may be responsible for the observed differences. First, Jungfraujoch is located in the central Alps, where orography-driven lifting of air masses leads frequently to mountain-wave (lenticularis) cirrus. These clouds are thicker than large-scale cirrus clouds but thinner than the cirrus formed as outflow of anvils or in warm conveyor belts. The second reason is the enhanced detectability of optically thin clouds at Jungfraujoch as a result of improved SNR (see Eq. 6). The alpine site is located at an altitude of $3500 \mathrm{~m}$ a.s.l., $3000 \mathrm{~m}$ above Zürich and $3400 \mathrm{~m}$ above Jülich. According to Eq. 1 the received signal depends on the inverse of the squared range between lidar and target. In addition, the Jungfraujoch is frequently above the boundary layer. Therefore, measurements from Jungfraujoch avoid strong beam extinction due to boundary layer aerosols.

Figure 5 provides vertical profiles of the cloud-mean SNR of the three stations, where the noise is obtained from Eq. (6). From the profiles it can be seen that the SNR of Jungfraujoch extends to greater heights by about $3 \mathrm{~km}$. This suggests that the increased detection rate of thin and subvisible cirrus clouds is a result of the increased SNR. Furthermore, the SNR at Jungfraujoch increases at heights above $13 \mathrm{~km}$ a.s.l. This suggests that the morphology of the clouds at these heights differs from the morphology of the highest clouds observed at Jülich and Zürich. The backscattering efficiency appears to be enhanced in these clouds, possibly because a large amount of small crystals formed in the observed cirrus clouds, when many ice crystals nucleated in the high supersaturations in rapid uplifts as they occur in lee waves above mountainous terrain (Lin et al., 1998a, b; Kärcher, 2003).

The number of detected subvisible cirrus as function of optical depth and cloud top altitude is depicted in Fig. 6. As expected, Jungfraujoch displays a larger fraction of subvisible cirrus as well as higher cirrus cloud tops. Therefore, we have evidence for both

a. the advantage of location of the higher Jungfraujoch as evidenced by the ability to measure thinner subvisible clouds (by about a factor 5) and

b. the special conditions above Jungfraujoch caused by orographic forcing, which affects the morphology of the cirrus as evidenced by the enhanced SNR at high altitudes.

It is interesting to see that at Jungfraujoch the lower detection limit in optical depth of a few times $10^{-5}$ is approached in a few cases. However, by far the most subvisible cirrus stay clearly above $\tau=10^{-4}$, proving that physical mechanisms prevent clouds so thin to survive for appreciable times. Nucleation is one such mechanism. In case these clouds nu-

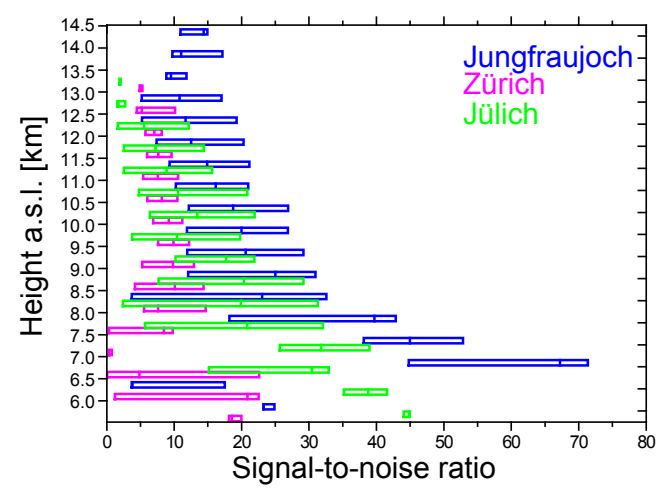

Figure 5. Vertical distribution of the signal-to-noise ratio of the detected cirrus clouds for Jungfraujoch, Jülich, and Zürich. The center line of each box plot represents the median. The left and right limits of the box plots mark the 25 th and 75 th percentiles, respectively.

cleate homogeneously, this is likely to happen in nucleation bursts, which will provide the newly formed clouds immediately a minimum optical depth. The same is true for heterogeneous nucleation when the nucleation barrier and the number of nuclei are at all significant. One mechanism that might lead to extremely low ice crystal number densities is the formation of fall streaks and subsequent dispersion of the particles. The rare occurrence of clouds with $\tau<5 \times 10^{-4}$ suggests that such mechanisms do not often lead to the formation of such thin clouds. The height distribution of the detected cirrus clouds in Fig. 6 agrees well with the cirrus clouds measured during the ECLIPS campaign (Winker and Vaughan, 1994).

To ensure that the highest cirrus clouds observed above Jungfraujoch were not volcanic particles, we have examined satellite measurements and found no indication for volcanic influences. The effect of the high altitude of Jungfraujoch can also be seen in the cloud tops at the different measurement sites (see Fig. 7a).

The cloud tops are higher above Jungfraujoch than above Zürich and Jülich. The retrieved cloud tops agree well with the observations by Sassen and Campbell (2001) in Salt Lake City $\left(40^{\circ} \mathrm{N}, 12^{\circ} \mathrm{W} ; 1520 \mathrm{~m}\right.$ a.s.l. $)$ as well as by Hoareau et al. (2013) in Haute Provence ( $44^{\circ} \mathrm{N}, 6^{\circ} \mathrm{E} ; 679$ m a.s.l.). The data from Salt Lake City and from Haute Provence were evaluated using schemes differing from FLICA and differing amongst themselves, which may influence the results. However, the cloud top altitudes are very similar for the five midlatitude stations. As Salt Lake City is located further south than the other sites, the slightly higher cloud tops may be a result of a higher tropopause being present over Salt Lake City compared to the other sites. Similarly, we see in Fig. 7b that the tropopause over Jülich, which is located further north than Zürich and Jungfraujoch, generally is lower. Between Zürich and Jungfraujoch, the tropopause reaches similar altitudes with a larger spread over Jungfraujoch (possibly due 


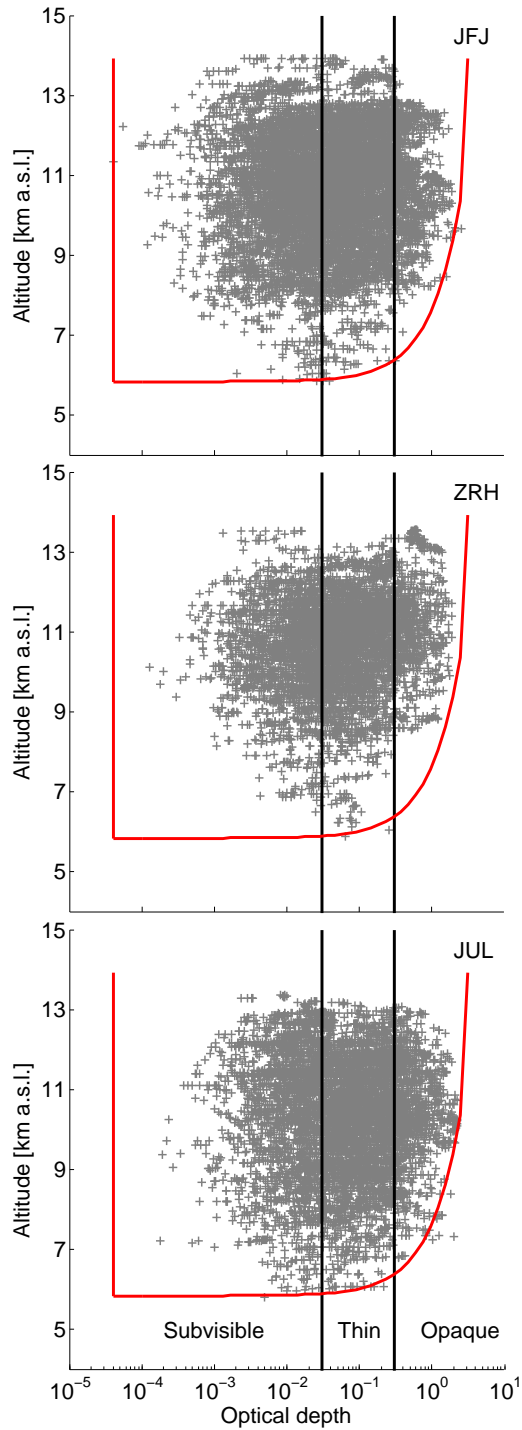

Figure 6. Scatter plots of cloud optical depths and cloud top altitudes for the cirrus detected above Jungfraujoch (JFJ), Zürich (ZRH), and Jülich (JUL). The red lines provide an indication of the range of data accessible by the lidar measurements: $\mathrm{AOD}_{\min }=$ $4 \times 10^{-5}, \mathrm{AOD}_{\max }=2.6$, and $\mathrm{Alt}_{\min }=5.8 \mathrm{~km}$. The lower edge of the accessible altitude is determined from $T<-38^{\circ} \mathrm{C}$. Thicker clouds are more likely to extend into lower, warmer levels and therefore are more likely to be excluded from the analysis.

to the Alpine heat low affecting the Jungfraujoch frequently during summertime).

\section{Cirrus radiative forcing}

\subsection{Method of calculation}

To quantify the net radiative effect, $\mathrm{CRF}_{\mathrm{NET}}$, for the cirrus clouds observed here we use the radiation model of Corti and Peter (2009a), which is a simplified model based on the

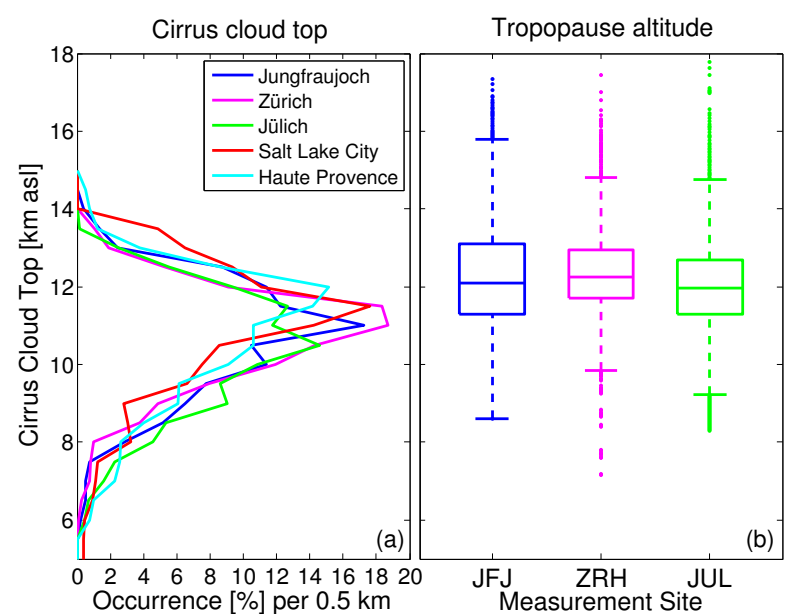

Figure 7. (a) Cloud tops (in $500 \mathrm{~m}$ steps) at the three sites of this study as well as in Salt Lake City by Sassen and Campbell (2001) and Haute Provence by Hoareau et al. (2013). (b) Tropopause derived from COSMO regional weather forecast model analyses $(2.2 \mathrm{~km}$ horizontal resolution for JFJ and $\mathrm{ZRH}, 6.6 \mathrm{~km}$ resolution for JUL).

more sophisticated $\mathrm{Fu}$-Liou radiative model (Fu and Liou, 1992, 1993). The accuracy of Corti and Peter (2009a) is better than $20 \%$ in comparison with the Fu-Liou model. The cloud radiative forcing due to shortwave radiation, $\mathrm{CRF}_{\mathrm{SW}}$, is dependent on the surface albedo, the solar zenith angle, as well as the cirrus cloud optical depth $\tau$ (see Eq. 13 of Corti and Peter, 2009a, for details). The longwave cloud radiative forcing, $\mathrm{CRF}_{\mathrm{LW}}$, is mainly determined by the temperature difference between the Earth's surface and the cirrus cloud top temperature and by the cloud optical depth $\tau$ (see Eq. 6 of Corti and Peter, 2009a, for details). The $\mathrm{CRF}_{\mathrm{LW}}$ further correlates well with the brightness temperature of the atmosphere, which is related to the outgoing longwave radiation at top of atmosphere (Schumann et al., 2012a). This correlation has not been considered in the model of Corti and Peter (2009a). CRF $_{\mathrm{NET}}$ is calculated as a superposition of these two effects (i.e., $\mathrm{CRF}_{\mathrm{NET}}=\mathrm{CRF}_{\mathrm{SW}}+\mathrm{CRF}_{\mathrm{LW}}$ ). The following parameters are needed as input for the calculation of the radiative effect:

- solar constant $S$

- solar zenith angle $Z$

- the surface albedo $\alpha$

- the cloud optical depth $\tau$

- the surface temperature $T_{\text {srf }}$

- the cloud top temperature $T_{\text {cld }}$.

The values of the solar constant $S$, multiplied by the fraction of the day that the sun is above the horizon, and the mean 
Table 3. Cirrus radiative forcing at the Top of Atmosphere in $\mathrm{W} \mathrm{m}^{-2}$ for Jungfraujoch, Zürich, and Jülich, as compared to $50^{\circ} \mathrm{N}$ zonally averaged and globally averaged values provided by Chen et al. (2000). Small numbers in CRF values indicate uncertainty ranges according to the last paragraph of Sect. 2.1. Small numbers in global cloud coverage indicates variability in zonal averages.

\begin{tabular}{lrrrrr}
\hline & JFJ & Zürich & Jülich & $50^{\circ} \mathrm{N}$ & global \\
\hline Cirrus coverage in $\%$ & 14 & 9 & 15 & 11 & $13_{-8}^{+7}$ \\
\hline Overcast & & & & & \\
CRF $_{\text {NET }}$ & $6.2_{-3.0}^{+0.7}$ & $10.6_{-5.3}^{+1.5}$ & $11.0_{-4.9}^{+1.4}$ & 2.0 & 5.4 \\
$\mathrm{CRF}_{\text {LW }}$ & $7.2_{-3.6}^{+1.0}$ & $12.3_{-6.1}^{+1.8}$ & $13.3_{-6.0}^{+1.6}$ & 20.1 & 30.7 \\
$\mathrm{CRF}_{\mathrm{SW}}$ & $-1.0_{-0.3}^{+0.5}$ & $-1.7_{-0.3}^{+0.8}$ & $-2.4_{-0.2}^{+1.1}$ & -18.1 & -25.3 \\
\hline $\mathrm{All} \mathrm{sky}_{\mathrm{CRF}}$ & & & & & \\
$\mathrm{CRF}_{\mathrm{LW}}$ & $0.9_{-0.4}^{+0.1}$ & $1.0_{-0.5}^{+0.1}$ & $1.6_{-0.7}^{+0.2}$ & 0.5 & 1.3 \\
$\mathrm{CRF}_{\mathrm{SW}}$ & $1.0_{-0.5}^{+0.1}$ & $1.1_{-0.6}^{+0.6}$ & $2.0_{-0.9}^{+0.2}$ & 3.0 & 5.5 \\
\hline
\end{tabular}

solar zenith angle $Z$ are set to $684 \mathrm{~W} \mathrm{~m}^{-2}$ and $60^{\circ}$ (daily mean conditions with zero incoming flux at nighttime), respectively, as suggested by the online version of the radiation model (Corti and Peter, 2009b). This results in an incident solar flux $I=684 \times 0.5=342 \mathrm{~W} \mathrm{~m}^{-2}$. The amplitude of the solar background noise in the lidar signal profiles is used to distinguish between day- and nighttime. We use an albedo of 0.3 (corresponding to the global average value). The cloud optical depth $\tau$ is automatically calculated in the FLICA for 5 min profiles as described in Sect. 2.2. The temperatures needed for the radiation model $\left(T_{\text {srf }}\right.$ and $\left.T_{\text {cld }}\right)$ are extracted from the COSMO-2 (for Jungfraujoch and Zürich) and COSMO-7 (for Jülich) model. The radiation model of Corti and Peter (2009a) is well suited to be used with lidar data, as the model does not require further information, such as ice crystal sizes or shapes, which the lidar measurements could not provide.

\subsection{Comparison of CRFs with previous studies}

We compare our computational results to satellite data, which have been averaged zonally at $50^{\circ} \mathrm{N}$ or globally and combined with a radiative transfer model (Chen et al., 2000). The results of this comparison are listed in Table 3 together with maximum possible uncertainty ranges (see last paragraph of Sect. 2.1). The "overcast values" (i.e., taking only cloudy values into account) consider the radiative effect under conditions with cirrus clouds, while the "all-sky values" also include conditions without cirrus by considering the cirrus occurrence frequency.

While the cirrus cloud coverage at $50^{\circ} \mathrm{N}$ from the satellitebased climatology International Satellite Cloud Climatology Project (ISCCP) (Chen et al., 2000) is similar to our observations, the ISCCP category of cirrus clouds show 1.5-3 times larger $\mathrm{CRF}_{\mathrm{LW}}$ and 1 order of magnitude larger $\mathrm{CRF}_{\mathrm{SW}}$. The difference in the $\mathrm{CRF}_{\mathrm{SW}}$ can only be explained in terms of a much larger optical depth $\tau$ of the clouds observed by the satellites. The $\mathrm{CRF}_{\mathrm{SW}}$ is mostly linearly dependent on the optical depth $\tau$, whereas the $\mathrm{CRF}_{\mathrm{LW}}$ depends linear on the temperature difference between ground and cloud as well as $\tau$ (see Corti and Peter, 2009a). Clouds with an increased optical depth are mostly found at lower altitudes, where the air is more humid. Thus the temperature difference is smaller, which results in a smaller increase of the $\mathrm{CRF}_{\mathrm{LW}}$ compared to the $\mathrm{CRF}_{\mathrm{SW}}$. Thus, warmer clouds with increased optical depth have larger negative $\mathrm{CRF}_{\mathrm{NET}}$. This explains the difference between the $\mathrm{CRF}_{\mathrm{SW}}$ and $\mathrm{CRF}_{\mathrm{LW}}$ in Chen et al. (2000), where more clouds with larger optical depth are included.

The reason for these (at first sight surprising) differences is the different definitions of "cirrus". First, FLICA detects only clouds with lower cloud edge colder than $-38^{\circ} \mathrm{C}$, which is typically above $7-8 \mathrm{~km}$. Chen et al. (2000) instead used a pressure threshold of $440 \mathrm{hPa}$ to separate clouds, which corresponds to an altitude of $6.3 \mathrm{~km}$ (standard atmosphere). The clouds in the range $6.3-7.5 \mathrm{~km}$ are missing in our study. Cirrostratus clouds with $\tau<3.6$ occur particularly in this altitude range. Second, although our criteria allow for thick clouds up to $\tau=3.6$ at altitudes clearly above lower edge, they cut clouds once their lower edge gets warmer than $-38^{\circ} \mathrm{C}$, which is more likely for thicker clouds (see rounded edge in the red boxes in Fig. 6). Third, while we count vertically distinct cirrus layers as separate clouds, the geostationary ISCCP weather satellites add the signal of vertically staggered layers, which increases $\tau$. Furthermore, it should be noted that satellite data reveal discrepancies amongst themselves (ISCCP, MISR, MODIS) with differences of 20-30\% in coverage of cirrus with $\tau<3.6$ (Marchand et al., 2010). Finally, the distribution of thicker cirrus with $\tau>0.3$ is zonally inhomogeneous, with clouds preferentially occurring at the continental east coasts.

In our study, we want to address only cirrus clouds and not mixed-phase clouds. Therefore, we have chosen a conservative limit towards lower, thicker clouds. Also, a temperature- 
based selection criterion is a better for separating different cloud types than a pressure-based criterion because temperature is the main microphysical parameter for cloud formation. As ISCCP is based on the analysis of weather satellite images, clouds still must have optical depths $\tau \geq 0.2$ in order to be reliably detected by such satellites (Rossow and Schiffer, 1999). Large uncertainties can also be traced to different approaches to partly cloudy pixels, which are $30 \mathrm{~km} \times 30 \mathrm{~km}$ for ISCCP and are treated as homogeneous, i.e., either cloud free or filled with a thinned homogeneous cloud (Pincus et al., 2012).

The overcast and all-sky $\mathrm{CRF}_{\mathrm{NET}}$ are significantly higher in Jülich than at Jungfraujoch, which is also clearly reflected in overcast and all-sky optical depths found in the ISCCP data (Soden and Donner, 1994). This may be related to the frequent low-pressure systems and fronts rolling in from the northwest across the North Sea. The related cirrus clouds weaken with distance from the coast.

The effect of the optically thicker clouds above Jülich compared to the Jungfraujoch is also evident in Fig. 8. The magenta lines indicate positive (i.e., warming) cirrus cloud radiative forcing (in $\mathrm{W} \mathrm{m}^{-2}$ ) as a function of altitude and optical depth calculated by the model of Corti and Peter (2009a) with mean temperature profiles from COSMO-2 (Jungfraujoch and Zürich) and COSMO-7 (Jülich) during the time period of our measurements. The blue isolines indicate negative (i.e., cooling) cirrus radiative forcing. A zero net effect, $\mathrm{CRF}_{\mathrm{NET}}=0$, is indicated by a cyan line. The occurrence frequency of the cirrus clouds measured at the different sites is color-coded. The occurrence frequency is categorized by 40 logarithmically spaced bins in optical depth between $10^{-4}$ and 10 and $500 \mathrm{~m}$ bins in cloud top altitude. From Fig. 8 we clearly see that the cirrus clouds observed in this study have all a positive (warming) $\mathrm{CRF}_{\mathrm{NET}}$. It is important to note that with the FLICA algorithm we do not find cirrostratus or cumulonimbus outflow clouds, i.e., no clouds with $\tau>3.6$. Of course, such clouds do exist also above our measurement sites. However, such clouds always have lower edges warmer than $-38^{\circ} \mathrm{C}$ and thus are not considered.

The pattern of cirrus cloud occurrence is quite similar above Jungfraujoch and Zürich, although the Jungfraujoch cirrus clouds show a slightly broader distribution in optical depths. Most cirrus layers are present at $11 \mathrm{~km}$ a.s.l. with optical depths between 0.01(0.04) and 0.2(0.4) above Jungfraujoch (in Zürich). Cirrus clouds above Jülich are frequent at altitudes between 8 and $12 \mathrm{~km}$ a.s.l. with optical depths ranging from 0.02 to 0.7 . This wider distribution of high occurrence frequencies in altitude is likely related to the high frequency of frontal systems crossing Jülich. The lower CRF $_{\text {NET }}$ above Jungfraujoch is visible in the shift towards thinner clouds at Jungfraujoch as compared to the other two measurement sites. Due to the lower SNR over Zürich and Jülich at cirrus altitude, these two sites underestimate the amount of subvisible cirrus clouds as compared to Jungfraujoch.
Besides Chen et al. (2000), other studies indicate also a general net warming effect of cirrus clouds in the midlatitudes. Oreopoulos and Rossow (2011) investigated the overall cloud radiative forcing based on a 24-year data set from the ISCCP. For cases with frequent occurrence of high clouds, a positive net cloud radiative forcing (warming) was obtained, whereas it was negative (cooling) for cases with frequent occurrence of low-level clouds. This confirms our results in which cirrus clouds create a positive net radiative forcing. A case study of Katagiri et al. (2010) found a cirrus cloud radiative forcing of $13.2 \mathrm{~W} \mathrm{~m}^{-2}$ at the Fukue observatory $\left(32^{\circ} \mathrm{N}\right.$, Japan) by a combination of MODIS satellite and ground-based observations. This value is similar to what we found for Zürich and Jülich and obviously larger than the respective value reported by Chen et al. (2000). Another study of Min et al. (2010) found a radiative forcing of cirrus of $36.5 \mathrm{~W} \mathrm{~m}^{-2}$ over China using also CALIOP and MODIS satellite data. The authors ascribe the high value to cirrus observations above the Tibetan plateau where very thick cirrus clouds with a mean optical depth of 1 are observed frequently. For the other parts of China lower values of $20 \mathrm{~W} \mathrm{~m}^{-2}$ are found. The radiative forcing of the lateral boundary of cirrus clouds observed with CALIOP is investigated by Li et al. (2014). The radiative effect of observed cirrus cloud edges is discussed. In the transition region of large cirrus, defined as their optically thin $\operatorname{rim}(\tau<0.3)$, which is often missed by satellite passive optical sensors such as MODIS, the $\mathrm{CRF}_{\mathrm{LW}}$ found to be still substantial $\left(\sim 10 \mathrm{~W} \mathrm{~m}^{-2}\right)$. This value is similar to our mean overcast radiative forcing of Zürich and Jülich and also demonstrates the sensitivity of cirrus cloud inhomogeneity on cloud forcing as found by $\mathrm{Gu}$ and Liou (2006). However, all these studies investigate single cases or different regions compared to our study. There is no study which investigates the cirrus radiative forcing over Europe.

In a study of Dupont et al. (2010), cirrus cloud observations over 2 years from the CALIPSO satellite lidar CALIOP are compared to four ground-based lidar stations (two sites in the USA and two in France) for their consistency of macrophysical and optical properties. They found larger discrepancies in the frequency distributions of cloud base, top, and thickness. They point out that the significant part of the deviations can be attributed to different sampling (seasonal, irregular sampling of ground-based stations, opaque low-level clouds). However, they found that for high cirrus clouds the optical depth distribution $\tau>0.1$ from ground stations and CALIOP is consistent within $10 \%$ using the same retrieval method. This shows that our optical depth distribution of all three stations is most likely not or only less affected by sampling issues of ground-based lidar compared to satellite measurements. 


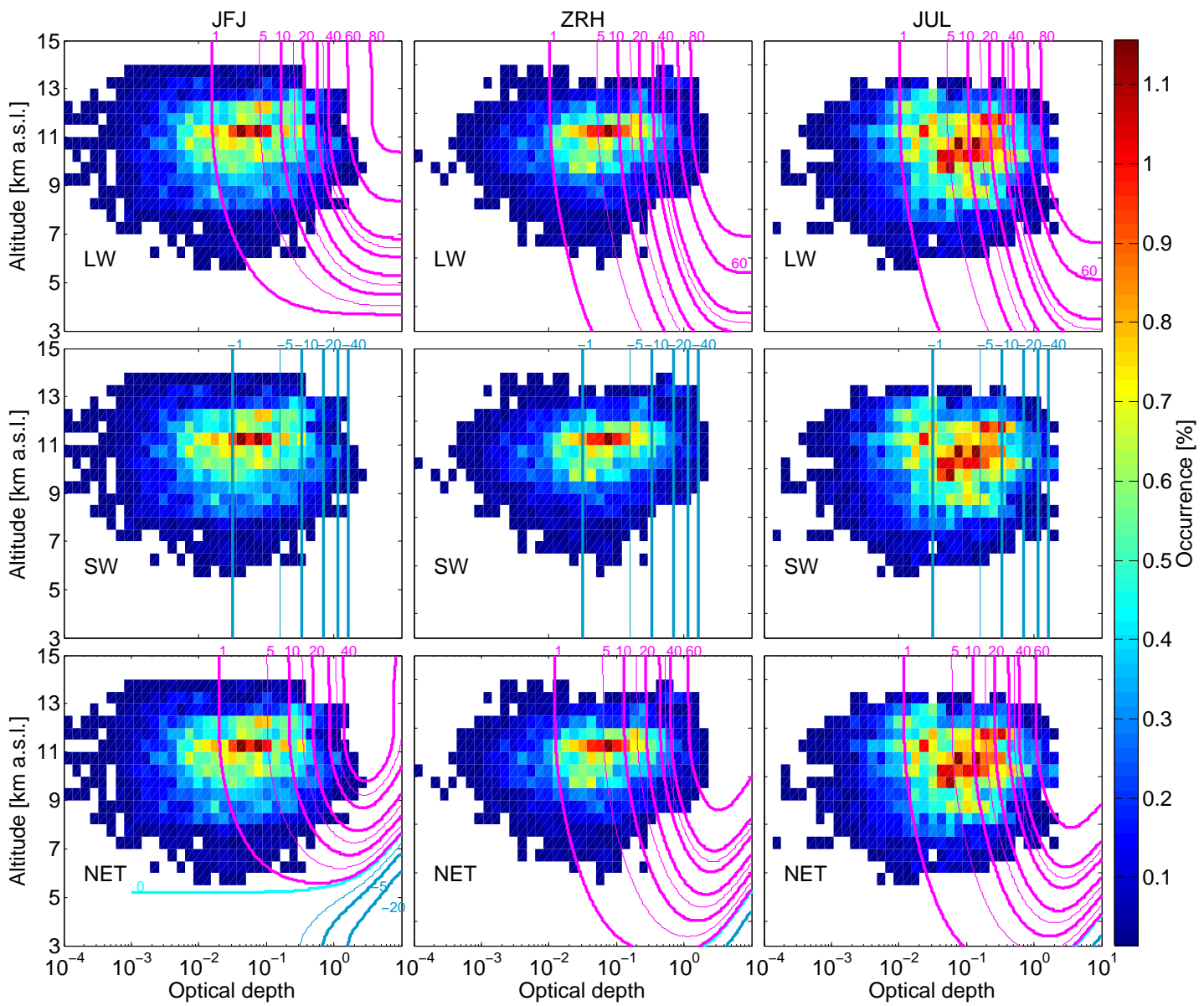

Figure 8. Cloud radiative forcing $(\mathrm{CRF})$ in $\mathrm{W} \mathrm{m}^{-2}$ for the different sites. Magenta/cyan/blue isolines: positive/zero/negative values in $\mathrm{W} \mathrm{m}^{-2}$ from the CRF model (Corti and Peter, 2009a). Color coding: Occurrence frequency of cirrus clouds as function of optical depth and cloud top altitude. First row: $\mathrm{CRF}_{\mathrm{LW}}$. Second row: $\mathrm{CRF}_{\mathrm{SW}}$. Third row: $\mathrm{CRF}_{\mathrm{NET}}$.

\subsection{Influence of subvisible cirrus on the net radiative forcing by cirrus clouds}

Subvisible cirrus clouds generally are not considered in numerical weather prediction models as their optical depths are considered to be too small. The overcast $\mathrm{CRF}_{\mathrm{NET}}$, divided into the categories defined by Sassen and Cho (1992), is shown in Fig. 9. We see that the subvisible cirrus clouds indeed have an effect on the $\mathrm{CRF}_{\mathrm{NET}}$. On average they contribute about $4 \%$ of the total $\mathrm{CRF}_{\mathrm{NET}}$ of cirrus clouds at Jungfraujoch and in Zürich and $3 \%$ in Jülich. The maximal effect of $6 \%$ is reached in Zürich during spring. As seen in Fig. 9, the thin and opaque cirrus clouds are the main contributors to $\mathrm{CRF}_{\mathrm{NET}}$ of cirrus clouds above each of the three stations, both by roughly equal shares (with a small dominance of opaque clouds).

Jungfraujoch displays the lowest $\mathrm{CRF}_{\mathrm{NET}}$ values throughout the whole year. This pattern is also seen in the optical depths shown in Fig. 4a. Generally, thinner clouds are detected above Jungfraujoch than at the other two sites. This

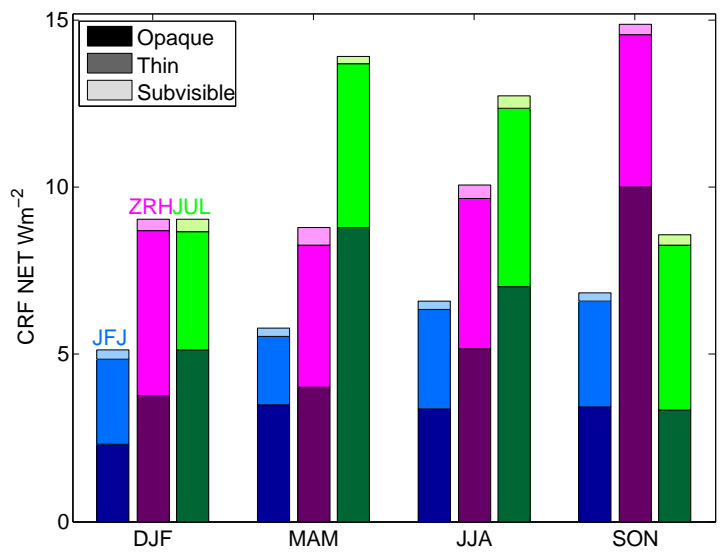

Figure 9. Cirrus radiative forcing under cloudy conditions, $\mathrm{CRF}_{\mathrm{NET}}$ (overcast), for the different seasons on Jungfraujoch (blue), in Zürich (pink), and in Jülich (green). Light shading: subvisible cirrus $(\tau<0.03)$. Medium shading: thin cirrus $(0.03<\tau<0.3)$. Dark shading: opaque cirrus $(0.3<\tau)$. 
influences the $\mathrm{CRF}_{\mathrm{NET}}$ : as more subvisible cirrus are observed at Jungfraujoch (cf. Table 2) and their contribution to $\mathrm{CRF}_{\mathrm{NET}}$ is smaller than the contribution by thin and opaque cirrus, this leads to a smaller $\mathrm{CRF}_{\mathrm{NET}}$ on Jungfraujoch. Summing up the percentages listed in Table 2, Jungfraujoch shows a fraction of $57 \%$ thin and opaque cirrus while Zürich and Jülich show occurrence frequencies of 65 and $68 \%$ thin and opaque clouds, respectively. These different sums result in the CRFs listed in Table 3 (taking note of the fact that the thresholds for the cirrus cloud categories (Sassen and Cho, 1992) are on a logarithmic scale).

\section{Conclusions}

We have presented a cirrus climatology based on $13000 \mathrm{~h}$ of lidar measurements at the three different midlatitude sites Jungfraujoch, Zürich and Jülich from 2010 to 2014. This extensive data set was evaluated using the newly developed FLICA algorithm, which combines a pixel-based cloud detection scheme with a classic lidar retrieval. With FLICA, the lidar data have been automatically evaluated. The retrieved backscatter coefficients are converted into extinction coefficients, which are corrected for multiple scattering to establish single-scattering extinction and then converted into optical depths.

We find mean optical depths of 0.12 for the cirrus measured over Jungfraujoch and of 0.14 and 0.17 , respectively, for Zürich and Jülich. While the cirrus coverage over Jungfraujoch and Jülich is almost equal, the amount of subvisible clouds detected over Jungfraujoch is significantly larger (cf. Table 2). Due to its unique location at $3580 \mathrm{~m}$ a.s.l., Jungfraujoch is an excellent site to measure subvisible cirrus clouds with a much improved SNR at cirrus altitude in comparison with the lower-lying stations. The mean cloud tops detected were located at $10.7 \mathrm{~km}$ in Zürich and on Jungfraujoch and at $10.3 \mathrm{~km}$ in Jülich, consistent with previous studies of Sassen and Campbell (2001) and Hoareau et al. (2013). Further, we have measured a temporal cirrus cloud coverage of $9-15 \%$ with a mean value of $13 \%$. This is consistent with the evaluation of the global CALIPSO measurements of Sassen et al. (2008).

Owing to the central location of the three measurement sites in Europe, a significant fraction of the thin cirrus observed within the present study might actually have originated from contrails. Clear indications for the occurrence of contrails were found on at least 1 day, given the optically and geometrically very thin cirrus observed in the lidar data. Liou et al. (1990) noted an increase of thin cirrus with increases in jet traffic. Our measurement sites are located in a region, where line-shaped contrails are ubiquitous (Mannstein et al., 1999; Meyer et al., 2002) as many flight routes cross this area. The observed optical depths are consistent with optical depths of contrail cirrus (Immler et al., 2008; Iwabuchi et al., 2012; Vázquez-Navarro et al., 2015). Furthermore, the cir- rus cloud cover determined in the present study is consistent with contrail cirrus calculations by Schumann et al. (2015). Therefore, it is likely that contrails contributed a fraction of the observed cirrus. The determination of the actual contribution of contrails to the cirrus cloud data set is, however, not subject of this study, considering that the applied data analysis algorithm FLICA cannot distinguish natural and contrail cirrus.

The evaluated cirrus cloud properties are used together with the radiation model of Corti and Peter (2009a) to estimate the cloud radiative forcing of the cirrus clouds. The optical depth as well as the cloud top temperature are the most important quantities determining the $\mathrm{CRF}_{\mathrm{NET}}$, and this dependence has been displayed in Fig. 8. Our results clearly confirm the warming effect of midlatitude cirrus clouds with optical depths below 3, corroborating previous studies. Using the radiation model of Corti and Peter (2009a), we find a net effect of $0.9 \mathrm{~W} \mathrm{~m}^{-2}$ for Jungfraujoch and $1.0 / 1.6 \mathrm{~W} \mathrm{~m}^{-2}$ for Zürich/Jülich. These values are larger by factors of 2-3 than the $50^{\circ} \mathrm{N}$ zonally averaged $\mathrm{CRF}_{\mathrm{NET}}$ derived by Chen et al. (2000) from satellite measurements in combination with a radiative transfer model. Even stronger deviations - but with opposite sign - are found for $C_{R F}$ and $C R F_{L W}$, where the zonally averaged data are higher than our CRF by up to 1 order of magnitude. This is due to the differing cloud definitions used by Chen et al. (2000) and by us and to the fact that the satellite-based zonal average includes regions with more pronounced thick cirrus (e.g., the continental east coasts).

Besides the radiation model of Corti and Peter (2009a) used for this study, other approaches exist that can be used to investigate the effect of other cloud properties besides optical depth on the cirrus radiative forcing. For instance, the radiation model of Schumann et al. (2012b) could be used to test the influence of various assumptions on particle habits and particle sizes (Markowicz and Witek, 2011).

The actual purpose of this work is the investigation of the thin $(0.03<\tau<0.3)$ and subvisible $\tau<0.03)$ cirrus clouds, which remain undetected by passive remote-sensing satellites (requiring typically $\tau>0.2$ ) and have so far not yet been systematically characterized in a climatological manner. The present study presents more than $13000 \mathrm{~h}$ of elastic backscatter lidar data, comprising more than 23000 individual cirrus clouds. Of these clouds about $40 \%$ were subvisible, $50 \%$ thin, and $10 \%$ opaque cirrus. In terms of fraction of cloud coverage, subvisible cirrus were observed during about $6 \%$, thin cirrus during about $7 \%$, and opaque cirrus during about $1.5 \%$ of the observation time. Seasonal variability in cirrus coverage shows characteristic autumn and spring maxima in agreement with satellite climatologies. Finally, in terms of cloud radiative forcing, all clouds discussed here show a positive, i.e., warming, effect. We calculate that subvisible cirrus contribute about $5 \%$, thin cirrus about $45 \%$, and opaque cirrus about $50 \%$ of the total cirrus radiative forcing. In order to exert a negative forcing, i.e., a cooling effect, clouds need to be either optically much thicker or in altitude much lower, 
or both, but we excluded these clouds by demanding that the lower edge of the cloud needs to be colder than $-38^{\circ} \mathrm{C}$ (cf. Fig. 8).

One important difference between the high ice clouds measured at Jungfraujoch compared to Jülich (with Zürich intermediate) is the possibility to measure thinner clouds above Jungfraujoch, which emphasizes the enhanced suitability of the high alpine measurement station to achieve a high SNR. Reasons for this are that the objects of interest are closer (and the backscattered signals scales with the square of the distance) and that the polluted boundary layer stays often below the Jungfraujoch station. The Jungfraujoch data show that the lower detection limit in optical depth of a few times $10^{-5}$ is approached in a few cases, but by far the most subvisible cirrus clearly stay above $\tau=10^{-4}$. We argue that this indicates that physical mechanisms prevent clouds from becoming and staying so thin for appreciable times. After formation, clouds will typically grow quickly and assume higher optical thicknesses. Conversely, evanescent clouds once having become so thin - will evaporate quickly, not leaving much time for their detection. This leads us to speculate that the Jungfraujoch measurements enable us to explore the very onset of cirrus formation and to possibly learn from the lidar measurements about the relative importance of homogeneous and heterogeneous ice nucleation.

\section{Data availability}

To get access to the data please contact Thomas Peter (thomas.peter@env.ethz.ch) at the ETH. We will gladly provide the lidar data, scripts and COSMO-data used in this study. Please note that the lidar raw data set contains $660 \mathrm{~GB}$ of data.

Acknowledgements. We are very grateful to Frank Wienhold for providing scripts for lidar evaluation and for input to an early version of the manuscript. We thank Uwe Weers, Marco Vecellio, and Edwin Hausammann for technical support with the lidar. We are particularly grateful to Joan and Martin Fischer as well as Maria and Urs Otz for excellent local support at the Jungfraujoch. Thanks also to Albert Ansmann for very helpful scientific input and to Andrew Huisman, Laura Revell, and Silke Gegenbauer for proof reading of an early stage of the manuscript. This work has been funded by GAW-CH, the Swiss branch of the Global Atmosphere Watch (GAW) programme, coordinated by the GAW-CH Office at MeteoSwiss in Switzerland.

Edited by: M. Tesche

\section{References}

Achtert, P., Khaplanov, M., Khosrawi, F., and Gumbel, J.: Pure rotational-Raman channels of the Esrange lidar for temperature and particle extinction measurements in the tropo- sphere and lower stratosphere, Atmos. Meas. Tech., 6, 91-98, doi:10.5194/amt-6-91-2013, 2013.

Ackermann, J.: The extinction-to-backscatter ratio of tropospheric aerosol: A numerical study, J. Atmos. Ocean. Tech., 15, 10431050, 1998.

Ansmann, A., Wandinger, U., Riebesell, M., Weitkamp, C., and Michaelis, W.: Independent measurement of extinction and backscatter profiles in cirrus clouds by using a combined Raman elastic-backscatter lidar, Appl. Optics, 31, 7113-7131, 1992.

Arshinov, Y. and Bobrovnikov, S.: Use of a Fabry-Perot interferometer to isolate pure rotational Raman spectra of diatomic molecules, Appl. Optics, 21, 4635-4638, doi:10.1364/AO.38.004635, 1999.

Boucher, O., Randal, D., Artaxo, P., Bretherton, C., Feingold, G., Forster, P., Kerminen, V.-M., Kondo, Y., Liao, H., Lohmann, U., Rasch, P., Satheesh, S. K., Sherwood, S., Stevens, B., and Zhang, X. Y.: Clouds and Aerosols, in: Climate Change 2013: The Physical Science Basis. Contribution of Working Group I to the Fifth Assessment Report of the Intergovernmental Panel on Climate Change, edited by: Stocker, T. F., Qin, D., Plattner, G.-K., Tignor, M., Allen, S. K., Boschung, J., Nauels, A., Xia, Y., Bex, V., and Midgley, P. M., Cambridge University Press, Cambridge, UK and New York, NY, USA, 571-658, doi:10.1017/CBO9781107415324.016, 2013.

Bucholtz, A.: Rayleigh-scattering calculations for the terrestrial atmosphere, Appl. Optics, 34, 2765-2773, 1995.

Burton, S. P., Ferrare, R. A., Hostetler, C. A., Hair, J. W., Rogers, R. R., Obland, M. D., Butler, C. F., Cook, A. L., Harper, D. B., and Froyd, K. D.: Aerosol classification using airborne High Spectral Resolution Lidar measurements - methodology and examples, Atmos. Meas. Tech., 5, 73-98, doi:10.5194/amt-5-73-2012, 2012.

Chen, T., Rossow, W. B., and Zhang, Y.: Radiative Effects of CloudType Variations, J. Climate, 13, 264-286, 2000.

Cirisan, A., Luo, B. P., Cirisan, A., Luo, B. P., Engel, I., Wienhold, F. G., Sprenger, M., Krieger, U. K., Weers, U., Romanens, G., Levrat, G., Jeannet, P., Ruffieux, D., Philipona, R., Calpini, B., Spichtinger, P., and Peter, T.: Balloon-borne match measurements of midlatitude cirrus clouds, Atmos. Chem. Phys., 14, 7341-7365, doi:10.5194/acp-14-7341-2014, 2014.

Cooney, J.: Measurement of Atmospheric Temperature Profiles by Raman Backscatter, J. Appl. Meteorol., 11, 108-112, 1972.

Corti, T. and Peter, T.: A simple model for cloud radiative forcing, Atmos. Chem. Phys., 9, 5751-5758, doi:10.5194/acp-9-57512009, 2009a.

Corti, T. and Peter, T.: A simple model for cloud radiative forcing, available at: http://iacweb.ethz.ch/php/toa/toa_high.php (last access: 16 July 2015), 2009b.

COSMO: Consortium for Small-scale Modeling, available at: http: //www.cosmo-model.org/, last access: 16 July 2015.

Cziczo, D. and Froyd, K. D.: Sampling the composition of cirrus ice residuals, Atmos. Res., 142, 15-31, 2014.

Dessler, A. E. and Yang, P.: The distribution of tropical thin cirrus clouds inferred from Terra MODIS data, J. Climate, 16, 1241-1247, doi:10.1175/15200442(2003)16<1241:TDOTTC>2.0.CO;2, 2003.

Dionisi, D., Keckhut, P., Liberti, G. L., Cardillo, F., and Congeduti, F.: Midlatitude cirrus classification at Rome Tor Vergata through a multichannel Raman-Mie-Rayleigh lidar, Atmos. 
Chem. Phys., 13, 11853-11868, doi:10.5194/acp-13-118532013, 2013.

Dupont, J. C., Haeffelin, M., Morille, Y., Noel, V., Keckhut, P., Winker, D., Comstock, J., Chervet, P., and Roblin, A.: Macrophysical and optical properties of midlatitude cirrus clouds from four ground-based lidars and collocated CALIOP observations, J. Geophys. Res.-Atmos., 115, D00H24, doi:10.1029/2009JD011943, 2010.

Ebert, E. and Curry, J.: A Parameterization of Ice Cloud Optical Properties for Climate Models, J. Geophys. Res., 97, 3831-3836, 1992.

Fréville, P., Montoux, N., Baray, J.-L., Chauvigné, A., Réveret, F., Hervo, M., Dionisi, D., Payen, G., and Sellegri, K.: LIDAR Developments at Clermont-Ferrand-France for Atmospheric Observation, Sensors (Basel, Switzerland), 15, 30413069, doi:10.3390/s150203041, 2015.

Fu, Q. and Liou, K. N.: On the Correlated K-Distribution Method for Radiative-Transfer in Nonhomogeneous Atmospheres, J. Atmos. Sci., 49, 2139-2156, 1992.

Fu, Q. and Liou, K. N.: Parameterization of the Radiative Properties of Cirrus Clouds, J. Atmos. Sci., 50, 2008-2025, 1993.

Fusina, F., Spichtinger, P., and Lohmann, U.: Impact of ice supersaturated regions and thin cirrus on radiation in the midlatitudes, J. Geophys. Res., 112, D24S14, doi:10.1029/2007JD008449, 2007.

Giannakaki, E., Balis, D. S., Amiridis, V., and Kazadzis, S.: Optical and geometrical characteristics of cirrus clouds over a Southern European lidar station, Atmos. Chem. Phys., 7, 5519-5530, doi:10.5194/acp-7-5519-2007, 2007.

Goldfarb, L., Keckhut, P., Chanin, M.-L., and Hauchecorne, A.: Cirrus climatological results from lidar measurements at OHP $\left(44^{\circ} \mathrm{N}, 6^{\circ} \mathrm{E}\right)$, Geophys. Res. Lett., 28, 1687-1690, doi:10.1029/2000GL012701, 2001.

Gu, Y. and Liou, K. N.: Cirrus cloud horizontal and vertical inhomogeneity effects in a GCM, Meteorol. Atmos. Phys., 91, 223-235, doi:10.1007/s00703-004-0099-2, 2006.

Hoareau, C., Keckhut, P., Noel, V., Chepfer, H., and Baray, J.L.: A decadal cirrus clouds climatology from ground-based and spaceborne lidars above the south of France $\left(43.9^{\circ} \mathrm{N}-5.7^{\circ} \mathrm{E}\right)$, Atmos. Chem. Phys., 13, 6951-6963, doi:10.5194/acp-13-69512013, 2013.

Hogan, R. J.: Fast Lidar and Radar Multiple-Scattering Models. Part I: Small-Angle Scattering Using the Photon Variance-Covariance Method, J. Atmos. Sci., 65, 3621-3635, doi:10.1175/2008JAS2642.1, 2008.

Ickes, L., Welti, A., Hoose, C., and Lohmann, U.: Classical nucleation theory of homogeneous freezing of water: thermodynamic and kinetic parameters, Phys. Chem. Chem. Phys., 17, 55145537, doi:10.1039/C4CP04184D, 2015.

Immler, F. and Schrems, O.: LIDAR measurements of cirrus clouds in the northern and southern midlatitudes during INCA $\left(55^{\circ} \mathrm{N}\right.$, $53^{\circ} \mathrm{S}$ ): A comparative study, Geophys. Res. Lett., 29, 56-1-56-4, doi:10.1029/2002GL015077, 2002.

Immler, F., Treffeisen, R., Engelbart, D., Krüger, K., and Schrems, O.: Cirrus, contrails, and ice supersaturated regions in high pressure systems at northern mid latitudes, Atmos. Chem. Phys., 8, 1689-1699, doi:10.5194/acp-8-1689-2008, 2008.

Iwabuchi, H., Yang, P., Liou, K. N., and Minnis, P.: Physical and optical properties of persistent contrails: Clima- tology and interpretation, J. Geophys. Res., 117, D06215, doi:10.1029/2011JD017020, 2012.

Kärcher, B.: Simulating gas-aerosol-cirrus interactions: Processoriented microphysical model and applications, Atmos. Chem. Phys., 3, 1645-1664, doi:10.5194/acp-3-1645-2003, 2003.

Katagiri, S., Kikuchi, N., Nakajima, T. Y., Higurashi, A., Shimizu, A., Matsui, I., Hayasaka, T., Sugimoto, N., Takamura, T., and Nakajima, T.: Cirrus Cloud Radiative Forcing Derived from Synergetic Use of MODIS Analyses and Ground-Based Observations, Sola, 6, 25-28, doi:10.2151/sola.2010-007, 2010.

Kienast-Sjögren, E., Miltenberger, A. K., Luo, B. P., and Peter, T.: Sensitivities of Lagrangian modelling of mid-latitude cirrus clouds to trajectory data quality, Atmos. Chem. Phys., 15, 74297447, doi:10.5194/acp-15-7429-2015, 2015.

Kim, Y., Kim, S.-W., Kim, M.-H., and Yoon, S.-C.: Geometric and optical properties of cirrus clouds inferred from three-year ground-based lidar and CALIOP measurements over Seoul, Korea, Atmos. Res., 139, 27-35, 2014.

Klett, J.: Stable analytical inversion solution for processing lidar returns, Appl. Optics, 20, 211-220, 1981.

Koop, T., Luo, B., Tsias, A., and Peter, T.: Water activity as the determinant for homogeneous ice nucleation in aqueous solutions, Nature, 406, 611-614, doi:10.1038/35020537, 2000.

Kovalev, V. and Eichinger, W.: Elastic Lidar, Wiley Online Library, doi:10.1002/0471643173, 2004.

Krämer, M., Rolf, C., Luebke, A., Afchine, A., Spelten, N., Costa, A., Meyer, J., Zöger, M., Smith, J., Herman, R. L., Buchholz, B., Ebert, V., Baumgardner, D., Borrmann, S., Klingebiel, M., and Avallone, L.: A microphysics guide to cirrus clouds - Part 1: Cirrus types, Atmos. Chem. Phys., 16, 3463-3483, doi:10.5194/acp16-3463-2016, 2016.

Larchevêque, G., Balin, I., Nessler, R., Quaglia, P., Simeonov, V., van den Bergh, H., and Calpini, B.: Development of a multiwavelength aerosol and water-vapor lidar at the Jungfraujoch Alpine Station ( $3580 \mathrm{~m}$ above sea level) in Switzerland, Appl. Optics, 41, 2781-2790, doi:10.1364/AO.41.002781, 2002.

Li, R., Cai, H. K., Fu, Y. F., Wang, Y., Min, Q. L., Guo, J. C., and Dong, X.: The optical properties and longwave radiative forcing in the lateral boundary of cirrus cloud, Geophys. Res. Lett., 41, 3666-3675, doi:10.1002/2014GL059432, 2014.

Lin, H., Noone, K. J., Ström, J., and Heymsfield, A. J.: Small Ice Crystals in Cirrus Clouds: A Model Study and Comparison with In Situ Observations, J. Atmos. Sci., 55, 1928-1939, doi:10.1175/1520-0469(1998)055<1928:SICICC >2.0.CO;2, $1998 \mathrm{a}$.

Lin, H., Noone, K. J., Ström, J., and Heymsfield, A. J.: Dynamical Influences on Cirrus Cloud Formation Process, J. Atmos. Sci., 55, 1928-1939, doi:10.1175/15200469(1998)055<1940:DIOCCF>2.0.CO;2, 1998b.

Liou, K. N.: An Introduction to Atmospheric Radiation, Second Edition, Academic Press, Elsevier Science, San Diego, USA, 2002.

Liou, K. N., Ou, S. C., and Koenig, G.: An investigation of the climatic effect of contrail cirrus, in: Air Traffic and the Environment - Background, Tendencies and Potential Global Atmospheric Effects, edited by: Schumann, U., Lecture Notes in Engineering, Springer Berlin, Germany, 154-169, 1990. 
Mannstein, H., Meyer, R., and Wendling, P.: Operational detection of contrails from NOAA-AVHRR data, Int. J. Remote Sens., 20, 1641-1660, doi:10.1080/014311699212650, 1999.

Marchand, R., Ackerman, T., Smyth, M., and Rossow, W. B.: A review of cloud top height and optical depth histograms from MISR, ISCCP, and MODIS, J. Geophys. Res., 115, D16206, doi:10.1029/2009JD013422, 2010.

Markowicz, K. M. and Witek, M.: Sensitivity study of global contrail radiative forcing due to particle shape, J. Geophys. Res., 116, D23203, doi:10.1029/2011JD016345, 2011.

Meyer, R., Mannstein, H., Meerkötter, R., Schumann, U., and Wendling, P.: Regional radiative forcing by line-shaped contrails derived from satellite data, J. Geophys. Res., 107, ACL 17-11ACL 17-15, doi:10.1029/2001jd000426, 2002.

Min, M., Wang, P. C., Campbell, J. R., Zong, X. M., and Li, Y.: Midlatitude cirrus cloud radiative forcing over China, J. Geophys. Res.-Atmos., 115, D20210, doi:10.1029/2010JD014161, 2010.

National Geophysical Data Center: 5-minute Gridded Global Relief Data (ETOPO5), National Geophysical Data Center, NOAA, available at: doi:10.7289/V5D798BF (last access: 13 August 2015), 1993.

Oreopoulos, L. and Rossow, W. B.: The cloud radiative effects of International Satellite Cloud Climatology Project weather states, J. Geophys. Res.-Atmos., 116, D12202, doi:10.1029/2010JD015472, 2011.

Pal, S. R., Carswell, A. I., Gordon, I., and Fong, A.: Lidar-Derived Cloud Optical Properties Obtained during the ECLIPS Program, J. Appl. Meteorol., 34, 2388-2399, 1995.

Pincus, R., Platnick, S., Ackerman, S. A., Hemler, R. S., and Hofmann, R. J. P.: Reconciling simulated and observed views of clouds: modis, iscep, and the limits of instrument simulators, J. Climate, 25, 4699-4720, doi:10.1175/JCLI-D-11-00267.1, 2012.

Platt, C. M., Young, S. A., Carswell, A. I., Pal, S. R., McCormick, M. P., Winker, D. M., DelGuasta, M., Stefanutti, L., Eberhard, W. L., Hardesty, M., Flamant, P. H., Valentin, R., Forgan, B., Gimmestad, G. G., Jäger, H., Khmelevtsov, S. S., Kolev, I., Kaprieolev, B., Lu, D., Sassen, K., Shamanaev, V. S., Uchino, O., Mizuno, Y., Wandinger, U., Weitkamp, C., Ansmann, A., and Woolridge, C.: The Experimental Cloud Lidar Pilot-Study (ECLIPS) for Cloud-Radiation Research, B. Am. Meteorol. Soc., 75, 1635-1654, 1994.

Platt, C. M. R. and Harshvardhan: Temperature Dependence of Cirrus Extinction: Implications for Climate Feedback, J. Geophys. Res., 93, 11051-11058, 1988.

Platt, C. M. R., Abshire, N. L., and McNice, G. T.: Some microphysical properties of an ice cloud from lidar observation of horizontally oriented crystals, J. Appl. Meteorol., 17, 1220-1224, 1978.

Pruppacher, H. R. and Klett, J. D.: Microphysics und Clouds and Precipitation, Kluwer Academic Publishers, New York, USA, ISBN: 0-7923-4211-9, 1997.

Radlach, M., Behrendt, A., and Wulfmeyer, V.: Scanning rotational Raman lidar at $355 \mathrm{~nm}$ for the measurement of tropospheric temperature fields, Atmos. Chem. Phys., 8, 159-169, doi:10.5194/acp-8-159-2008, 2008.

Reichardt, J., Reichardt, S., Hess, M., and McGee, T. J.: Correlations among the optical properties of cirrus-cloud particles: Microphysical interpretation, J. Geophys. Res.-Atmos., 107, 21562202, doi:10.1029/2002JD002589, 2002.
Rolf, C.: Lidar observations of natural and volcanic-ash-induced cirrus clouds, Bergische Universität Wuppertal, Germany, 2012.

Rolf, C., Krämer, M., Schiller, C., Hildebrandt, M., and Riese, M.: Lidar observation and model simulation of a volcanicash-induced cirrus cloud during the Eyjafjallajökull eruption, Atmos. Chem. Phys., 12, 10281-10294, doi:10.5194/acp-1210281-2012, 2012.

Rossow, W. B. and Schiffer, R. A.: Advances in understanding clouds from ISCCP, B. Am. Meteorol. Soc., 80, 2261-2287. doi:10.1175/1520-0477(1999)080<2261:AIUCFI>2.0.CO;2, 1999.

Sassen, K. and Benson, S.: A Midlatitude Cirrus Cloud Climatology from the Facility for Atmospheric Remote Sensing. Part II: Microphysical Properties Derived from Lidar Depolarization, J. Atmos. Sci., 58, 2103-2112, doi:10.1175/15200469(2001)058<2103:AMCCCF>2.0.CO;2, 2001.

Sassen, K. and Campbell, J. R.: A Midlatitude Cirrus Cloud Climatology from the Facility for Atmospheric Remote Sensing. Part I: Macrophysical and Synoptic Properties, J. Atmos. Sci., 58, 481-496, doi:10.1175/15200469(2001)058<0481:AMCCCF>2.0.CO;2, 2001.

Sassen, K. and Cho, B. S.: Subvisual-Thin Cirrus Lidar Dataset for Satellite Verification and Climatological Research, J. Appl. Meteorol., 31, 1275-1285, doi:10.1175/15200450(1992)031<1275:STCLDF>2.0.CO;2, 1992.

Sassen, K. and Comstock, J. M.: A Midlatitude Cirrus Cloud Climatology from the Facility for Atmospheric Remote Sensing. Part III: Radiative Properties, J. Atmos. Sci., 58, 2113-2127, doi:10.1175/1520-0469(2001)058<2113:AMCCCF>2.0.CO;2, 2001.

Sassen, K., Zhu, J., and Benson, S.: Midlatitude cirrus cloud climatology from the Facility for Atmospheric Remote Sensing. IV. Optical displays, Appl. Optics, 42, 332-341, 2003.

Sassen, K., Wang, L., Starr, D. O'C., Comstock, J. M., and Quante, M.: A Midlatitude Cirrus Cloud Climatology from the Facility for Atmospheric Remote Sensing. Part V: Cloud Structural Properties, J. Atmos. Sci., 64, 2483-2501, doi:10.1175/JAS3949.1, 2007.

Sassen, K., Wang, Z., and Liu, D.: Global distribution of cirrus clouds from CloudSat/Cloud-Aerosol Lidar and Infrared Pathfinder Satellite Observations (CALIPSO) measurements, J. Geophys. Res., 118, D00A12, doi:10.1029/2008JD009972, 2008.

Schotland, R. M., Sassen, K., and Stone, R.: Observations by Lidar of Linear Depolarization Ratios for Hydrometeors, J. Appl. Meteorol., 10, 1011-1017, doi:10.1175/15200450(1971)010<1011:OBLOLD>2.0.CO;2, 1971.

Schumann, U., Graf, K., Mannstein, H., and Mayer, B.: Contrails: Visible aviation induced climate impact, in: Atmospheric Physics - Background - Methods - Trends, edited by: Schumann, U., 239-257, Springer, Berlin, Heidelberg, Germany, doi:10.1007/978-3-642-30183-4_15, 2012a.

Schumann, U., Mayer, B., Graf, K., and Mannstein, H.: A parametric radiative forcing model for contrail cirrus, J. Appl. Meteorol. Clim., 51, 1391-1406, doi:10.1175/JAMC-D-11-0242.1, 2012 b.

Schumann, U., Penner, J. E., Chen, Y., Zhou, C., and Graf, K.: Dehydration effects from contrails in a coupled contrail-climate model, Atmos. Chem. Phys., 15, 11179-11199, doi:10.5194/acp15-11179-2015, 2015. 
Seifert, P., Ansmann, A., Müller, D., Wandinger, U., Althausen, D., Heymsfield, A. J., Massie, S. T., and Schmitt, C.: Cirrus optical properties observed with lidar, radiosonde, and satellite over the tropical Indian Ocean during the aerosol-polluted northeast and clean maritime southwest monsoon, J. Geophys. Res.-Atmos., 112, 2156-2202, doi:10.1029/2006JD008352, 2007.

She, S.: Spectral structure of laser light scattering revisited: bandwidths of nonresonant scattering lidars, Appl. Optics, 40, 48754884, 2001.

Soden, B. J. and Donner, L. J.: Evaluation of a GCM cirrus parameterization using satellite observations, J. Geophys. Res., 99, 14401-14413, doi:10.1029/94JD00963, 1994.

Solomon, S., Qin, D., Manning, M., Chen, Z., Marquis, M., Averyt, K. B., Tignor, M., and Miller, H. L. (Eds.): IPCC 2007: Climate Change 2007: The Physical Science Basis. Contribution of Working Group I to the Fourth Assessment Report of the Intergovernmental Panel on Climate Change, Cambridge University Press, Cambridge, UK and New York, NY, USA, 2007.

Vázquez-Navarro, M., Mannstein, H., and Kox, S.: Contrail life cycle and properties from 1 year of MSG/SEVIRI rapid-scan images, Atmos. Chem. Phys., 15, 8739-8749, doi:10.5194/acp-158739-2015, 2015.

Wandinger, U.: Multiple-scattering influence on extinction- and backscatter-coefficient measurements with Raman and highspectral-resolution lidars, Appl. Optics, 37, 417-427, 1998.
Wandinger, U.: Raman Lidar in LIDAR: Range-Resolved Optical Remote Sensing of the Atmosphere, Springer, New York, USA, 241-271, 2005.

Wandinger, U., Tesche, M., Seifert, P., Ansmann, A., Müller, D., and Althausen, D.: Size matters: Influence of multiple scattering on CALIPSO light-extinction profiling in desert dust, Geophys. Res. Lett., 37, L10801, doi:10.1029/2010GL042815, 2010.

Wang, Z. and Sassen, K.: Cirrus cloud microphysical property retrieval using lidar and radar measurements. Part II: Midlatitude cirrus microphysical and radiative properties, J. Atmos. Sci., 59, 2291-2302, 2002.

Westbrook, C. D., Illingworth, A. J., O'Connor, E. J., and Hogan, R. J: Doppler lidar measurements of oriented planar ice crystals falling from supercooled and glaciated layer clouds, Q. J. Roy. Meteor. Soc., 136, 260-276, doi:10.1002/qj.528, 2010.

Winker, D. M. and Vaughan, M. A.: Vertical distribution of clouds over Hampton, Virginia observed by lidar under the ECLIPS and FIRE ETO programs, Atmos. Res., 34, 117-133, 1994.

Zieger, P., Kienast-Sjögren, E., Starace, M., von Bismarck, J., Bukowiecki, N., Baltensperger, U., Wienhold, F. G., Peter, T., Ruhtz, T., Collaud Coen, M., Vuilleumier, L., Maier, O., Emili, E., Popp, C., and Weingartner, E.: Spatial variation of aerosol optical properties around the high-alpine site Jungfraujoch (3580 ma.s.1.), Atmos. Chem. Phys., 12, 72317249, doi:10.5194/acp-12-7231-2012, 2012. 